\title{
The dual regulation of apoptosis by Flavivirus
}

\author{
Yuhong Pan ${ }^{1}$, Anchun Cheng ${ }^{1}$, Mingshu Wang ${ }^{1}$, Zhong Yin ${ }^{1}$, and Ren-Yong Jia ${ }^{1}$ \\ ${ }^{1}$ Sichuan Agricultural University - Chengdu Campus
}

December 1, 2020

\begin{abstract}
Apoptosis is a form of programmed cell death, which maintains cellular homeostasis by eliminating pathogen-infected cells. It contains three signaling pathways: death receptor pathway, mitochondria-mediated pathway and endoplasmic reticulum pathway. Its importance in host defenses is highlighted by the observation that many viruses evade, hinder or destroy apoptosis, thereby weakening the host's immune response. Flaviviruses such as Dengue virus, Japanese encephalitis virus and West Nile virus utilize various strategies to activate or inhibit cell apoptosis. This article reviews the research progress of apoptosis mechanism during flaviviruses infection, including flaviviruses proteins to regulate apoptosis by interacting with host proteins, as well as various signaling pathways involved in flaviviruses-induced apoptosis, which provides a scientific basis for understanding the pathogenesis of flaviviruses and helps in developing an effective antiviral therapy.
\end{abstract}

Review

The dual regulation of apoptosis by Flavivirus

Running title: apoptosis regulation by Flavivirus

Yuhong Pan $^{1,2,3}$, Anchun Cheng ${ }^{1,2,3, *}$, Mingshu Wang ${ }^{1,2,3}$, Zhongqiong $\mathrm{Yin}^{3}$ and Renyong $\mathrm{Jia}^{1,2,3},^{*}$

1 Research Center of Avian Disease, College of Veterinary Medicine, Sichuan Agricultural University, Chengdu, Sichuan, 611130, China;

${ }^{2}$ Institute of Preventive Veterinary Medicine, Sichuan Agricultural University, Chengdu, Sichuan, 611130, China;

${ }^{3}$ Key Laboratory of Animal Disease and Human Health of Sichuan Province, Chengdu, Sichuan, 611130, China

* Corresponding authors at: Institute of Preventive Veterinary Medicine, College of Veterinary Medicine, Sichuan Agricultural University, Chengdu, Sichuan, 611130, China.

E-mail addresses:jiary@sicau.edu.cn (R.Jia),chenganchun@vip.163.com(A.Cheng)

Abstract: Apoptosis is a form of programmed cell death, which maintains cellular homeostasis by eliminating pathogen-infected cells. It contains three signaling pathways: death receptor pathway, mitochondriamediated pathway and endoplasmic reticulum pathway. Its importance in host defenses is highlighted by the observation that many viruses evade, hinder or destroy apoptosis, thereby weakening the host's immune response. Flaviviruses such as Dengue virus, Japanese encephalitis virus and West Nile virus utilize various strategies to activate or inhibit cell apoptosis. This article reviews the research progress of apoptosis mechanism during flaviviruses infection, including flaviviruses proteins to regulate apoptosis by interacting with 
host proteins, as well as various signaling pathways involved in flaviviruses-induced apoptosis, which provides a scientific basis for understanding the pathogenesis of flaviviruses and helps in developing an effective antiviral therapy.

Keywords: apoptosis; flavivirus; Dengue virus; Japanese encephalitis virus, West Nile virus; Zika virus

\section{Flavivirus}

Flavivirus belong to the Flaviviridae family and have 70 different antigen-related members. Flavivirus is an emerging arthropod-borne virus that causes huge global health problems. According to the epidemic reports, Dengue virus (DENV), Japanese Encephalitis Virus (JEV), West Nile virus (WNV), Zika virus (ZIKV), Yellow fever virus (YFV) and tick-borne Encephalitis virus (TBEV) are major human pathogenic flaviviruses(Rastogi, Sharma, \& Singh, 2016). They are responsible for the illness ranging from mild flu symptoms to severe hemorrhagic, neurological and cognitive manifestations that cause death.

\section{Structure}

Flavivirus is a single-stranded, positive-polarity RNA virus with a genome of approximately $11 \mathrm{~kb}$, which has only one open reading frame (ORF) flanked by a 5'-untranslated region (UTR) and a 3'-untranslated region (Figure 1). The ORF encodes a polyprotein of $\sim 3400$ aa residues, which is cleaved by viral and host protease to produce three structural proteins (capsid [C]; precursor of $\mathrm{M}[\mathrm{prM}]$ and envelope $[\mathrm{E}]$ ) and seven nonstructural (NS) proteins (NS1, NS2A/2B, NS3, NS4A/4B and NS5)(Juan Huang et al., 2018; Tao et al., 2012; Wanjun et al., 2012).

\subsection{Life cycle}

Flaviviruses share a common mechanism of propagation in host cells. Initially, they enter target cells via receptor-mediated endocytosis and transfer to endosomes. The acidic environment in the endosomal lumen triggers conformational changes of the glycoprotein on the surface of the virus, causing the virus envelope to fuse with the endosomal membranes(Bressanelli et al., 2004). Subsequently, the disintegration of the viral capsid ('uncoating') delivers the RNA genome to the cytoplasm, completing the entry process. The positive polarity genomes then serve as templates for translation and replication. When the viral RNA is translated into a precursor protein at the endoplasmic reticulum (ER), this polypeptide is coordinated and post-translationally processed by the viral and host protease to produce three structural proteins and seven nonstructural proteins. After translation of input genomic RNA, the RNA-dependent RNA polymerase (RdRp) NS5 copies complementary negative-stand RNA from genomic RNA, which serves as a template for the synthesis of new positive-strand viral RNA(Brinton, 2002). Immature, non-infectious virions are assembled in the ER, where viral RNA is complexed with protein $\mathrm{C}$ and packaged into an ER-derived lipid bilayer containing heterodimers of prM and E proteins(Lorenz et al., 2003; Mackenzie \& Westaway, 2001). The prM protein acts as a scaffold to prevent the virus from fusing prematurely during transport out of the cell(L. Li et al., 2008). Subsequently, PrM is cleaved into M by the cellular protease furin in the trans-Golgi network(I. M. Yu et al., 2008). Finally, mature infectious virus particles are released outside the cell by exocytosis (Figure 2).

\section{Apoptosis}

Apoptosis, also known as programmed cell death (PCD), is a self-protection mechanism used by multicellular organisms to eliminate senescent, damaged, or pathogen-infected cells. Apoptosis is regulated by two classical signaling pathways: the intrinsic and the extrinsic apoptotic pathways. Apoptotic cells are manifested by cell shrinkage, chromatin aggregation, DNA fragmentation, mitochondrial swelling, and finally the formation of apoptotic bodies, which are cleared by phagocytes(Kennedy, 2015). Studies have found that apoptosis plays an important role in the pathogenesis of viral infections. As a key innate defense mechanism, it inhibits virus replication and clears virus-infected cells(Benedict, Norris, \& Ware, 2002), which is of great significance for maintaining the healthy development of organism and the normal function of the immune system(X. Liu, Kim, Yang, Jemmerson, \& Wang, 1996). However, many viruses have evolved strategies to prevent or delay the occurrence of apoptosis during virus replication until sufficient progeny viruses are produced. Moreover, 
some viruses-induced apoptosis can enhance the spread of the virus, leading to tissue damage and disease. In this article, we focus on reviewing the roles played by flavivirus in the regulation of cell apoptosis, and understanding the mechanism of flavivirus regulating apoptosis will be helpful for future research.

\subsection{The intrinsic pathway}

The occurrence of the intrinsic apoptosis signal pathway of apoptosis mainly involves various non-receptormediated stimuli, generating intracellular signals, and directly acting on intracellular target (mitochondria), leading to apoptosis. Stimulants that cause endogenous apoptosis act in an active or passive manner. Passive signals include the loss of specific growth factors, hormones and cytokines, leading to an unlimited death program, thereby triggering cell apoptosis(Papaianni et al., 2015). Other stimuli that act in an active manner include but are not limited to radiation, toxins, hypoxia, high fever, viral infections and free radicals.

The mitochondrial pathway in apoptosis is mainly regulated by members of the Bcl-2 family proteins(Ashkenazi \& Salvesen, 2014; Papaianni et al., 2015). Bcl-2 family proteins have pro-apoptotic or anti-apoptotic effects. So far, 25 genes have been identified in the Bcl-2 family. Anti-apoptotic proteins include Bcl-2, Bcl- $\mathrm{X}_{\mathrm{L}}$, Bcl-x, Bcl-XS, Bcl-w and BAG, pro-apoptotic proteins include Bax, Bak, Bid, Bad, Bim, Bcl-10, Bik and Blk(Borner \& Andrews, 2014; Kilbride \& Prehn, 2013; Wong \& Puthalakath, 2008). These proteins all play a role in determining whether a cell undergoes apoptosis. Studies have found that the main mechanism of Bcl-2 family protein function is to modulate the mitochondrial membrane permeability to regulate the release of cytochrome c (Cyt-c).

The stimulus causes changes in the inner mitochondrial membrane, leading to the opening of the permeability transition pore (PTP), the loss of mitochondrial membrane potential (MMP), and the release of two groups of pro-apoptotic proteins from the membrane space into the cytoplasm(Tait \& Green, 2010) (Figure 3). The first group contains Cyt-c, DIABLO/Smac and serine protease HtraA2/Omi(Garrido et al., 2006; van Loo et al., 2002). These proteins activate the caspases-dependent mitochondrial pathway, cyt-c binds and activates apaf-1 and procaspase-9 to form "apoptosome"(Yuan \& Akey, 2013). The accumulation of procaspase-9 leads to the activation of caspase- 9 , and caspase- 9 triggers the caspase cascade, then the activated caspase$3 / 6 / 7$ executes apoptosis. DIABLO/Smac and serine protease HtrA2/Omi have been reported to inhibit IAPs (inhibitors of apoptotic protein) and promote apoptosis(Schimmer, 2004). The second group of proapoptotic proteins includes AIF (apoptosis-inducing factor) and EndoG (endonuclease G), and the functions of AIF and EndoG are independent of caspases. These two proteins are released from the mitochondria when apoptosis occurs, and as a late event, it occurs in the dying cells. AIF translocates into the nucleus, causing DNA fragmentation and condensation of peripheral nuclear chromatin(Joza et al., 2001). EndoG can also be translocated into the nucleus to cut off nuclear chromatin and produce oligomeric nucleosome DNA fragments(Jang et al., 2015). As a site for protein synthesis and processing, the ER is imbalanced due to physical and chemical stimulation or infection of pathogenic microorganisms, resulting in the inability of protein folding or misfolding. When these conformationally dissimilated proteins accumulate in the ER and cannot be effectively eliminated, the cells will initiate an unfolded protein response (UPR). Long-term activation of UPR can trigger cell apoptosis through IRE1 (inositol requiring protein-1), PERK (protein kinase RNA-like ER kinase) and ATF6 (activating transcription factor-6) pathways, which are connected with mitochondria-mediated apoptosis pathway(Verma \& Datta, 2012). First, phosphorylated IRE1 recruits TRAF2 (TNF receptor-associated factor 2) and triggers a cascade of phosphorylation events, such as the activation of ASK1 (apoptosis signaling kinase 1), and ultimately phosphorylates and activates JNK. Then, JNK activates pro-apoptotic genes Bax, Bak, Bim, PUMA and NOXA, these genes are transferred to the mitochondrial to initiate apoptosis(Upton et al., 2012). The homomultimerization and autophosphorylation of PERK lead to phosphorylation of eIF2 $\alpha$ (eukaryotic translation initiation factor $2 \alpha$ ), which increases the translation of ATF4 (activating transcription factor 4). Then, ATF4 upregulates the expression of CHOP (C/EBP-homologous protein) and activates apoptosis(Tabas \& Ron, 2011). CHOP can reduce the expression of anti-apoptotic genes Bcl-2 and Bcl- $\mathrm{X}_{\mathrm{L}}$ (Puthalakath et al., 2007). ATF6 binds to the ER membrane, but when protein homeostasis is disrupted, ATF6 then migrates to the Golgi apparatus to undergo cleavage, first by Site 1 Protease (S1P) and then by Site 2 Protease (S2P)(Ye et al., 2000), cleaved ATF6 can also promote 
cell apoptosis via upregulating of CHOP(Hirsch, Weiwad, Prell, \& Ferrari, 2014; Morishima, Nakanishi, \& Nakano, 2011).

\subsection{The extrinsic pathway}

The extrinsic apoptotic pathway is mediated by specific death receptors (DRs) on the cell membrane, the DRs are members of the TNF (tumor necrosis factor) superfamily(Locksley, Killeen, \& Lenardo, 2001). The death domain (DD) of DRs transmits death signals from the cell surface to the intracellular signaling pathway. So far, ligands and corresponding death receptors include FasL/Fas, TNF- $\alpha$ /TNFR1, Apo3L/DR3, Apo2L/DR4 and Apo2L/DR5. When the ligand binds to the receptor, it recruits cytoplasmic linker protein and binds to the receptor through death domain(Rubio-Moscardo et al., 2005; Suliman, Lam, Datta, \& Srivastava, 2001). Taking the FasL/Fas model as an example, the binding of FasL (Fas ligand) to Fas can recruit the linker protein FADD (Fas-associated protein with death domain) through the death domain(Wajant, 2002) (Figure 4). Then FADD combined with procaspase- $8 / 10$ through the dimerization of the death effector domain (DED) to form a death-inducing signaling complex (DISC), leading to autoproteolytic cleavage of procaspase$8 / 10$ (Kischkel et al., 1995). The activated caspase-8/10 have enzymatic activity and can hydrolyze caspase$3 / 6 / 7$ to induce apoptosis(Ashkenazi, 2008). There is a related cross-connection between the death receptor (extrinsic) pathway and the mitochondrial (intrinsic) pathway. In certain cells, activated caspase- 8 cleaves the pro-apoptotic protein Bid to create truncated Bid (tBid), thereby activating the mitochondria-mediated apoptosis signaling pathway(K. Huang et al., 2016). TNFR1 is activated by the binding of its respective ligand TNF. TNFR1 recruits TRADD, an adaptor protein that can bind to TNF receptor-associated factors (TRAFs), receptor-interacting protein kinase (RIP1) and cellular IAPs to form an initial membrane complex (complex I), which stimulates the NF- $x$ B pathway to facilitate cell apoptosis(Mahmood \& Shukla, 2010). The initially formed TRADD-RIP1-TRAFs complex I then assembles into the cytoplasmic apoptotic complex (complex II). There are two types of cytoplasmic complex II, TRADD recruits FADD and caspase-8 to form TRADD-dependent complex IIA, RIP1 recruits FADD and caspase- 8 to form complex IIB, and cIAPs can negatively regulate complex IIB. Both complex IIA and IIB can trigger apoptosis by activating caspase8(Galluzzi, Kepp, \& Kroemer, 2012; Pobezinskaya \& Liu, 2012).

\section{Apoptosis during Flavivirus-infection}

\subsection{Dengue Virus}

\subsubsection{DENV regulation of apoptosis}

Dengue virus is a serious arbovirus and the most lethal among all Flavivirus members. There are four distinct DENV strains (DENV 1-4) in serology. Dengue infection may cause diverse pathogenic conditions, ranging from mild-flu like febrile syndrome (dengue fever) to very serious conditions caused by infection with the second serotype, the dengue hemorrhagic fever (DHF) or the dengue shock syndrome (DSS)(Courageot, Catteau, \& Desprès, 2003).

\section{DENV1}

Previous studies have shown that DENV1 infection can lead to typical apoptosis in a variety of human and animal cells including BHK, HUH-7, Vero and mouse neuroblastoma (Neuro 2a) cell lines(Desprès, Flamand, Ceccaldi, \& Deubel, 1996; Nasirudeen, Li, \& Ding, 2008). And DENV1 replicated in human hepatoma cells (HepG2) leads to the activation of transcription factor NF- $x \mathrm{~B}$ and induces apoptosis(Marianneau, Cardona, Edelman, Deubel, \& Desprès, 1997). Another study found that accumulation of DENV1 viral protein in the ER, rather than the release of virus, can induce ER stress and activate the apoptosis pathway. In addition, DENV1 C and prM proteins have been shown to trigger MMP down-regulation and p53 expression in HUH-7 cells, suggesting that mitochondria- and p53-mediated pathways are very likely to participate in DENV1induced apoptosis(Nasirudeen et al., 2008). The regulatory effects of DENV and its proteins on apoptosis are summarized in Table 1.

\section{DENV2}




\section{Pro-apoptosis}

Autopsy of fatal DHF/DSS cases caused by DENV2 demonstrated apoptotic cells in liver, brain, intestinal and lung tissues, and the apoptotic microvascular endothelial cells (ECs) in intestinal and pulmonary tissues explain the patient's plasma leakage(Limonta, Capó, Torres, Pérez, \& Guzmán, 2007). DENV2 infection of human ECs leads to up-regulation of IL-8 (interleukin-8) and RANTES (regulated upon activation normal $\mathrm{T}$ cell expressed and secreted factor), these cytokines accumulate at serosal sites and cause local vascular leakage, which has been observed to accompany apoptosis(Avirutnan, Malasit, Seliger, Bhakdi, \& Husmann, 1998). Further research found that DENV2 induces ECs apoptosis through XIAP-associated factor 1 (XAF1)dependent pathway, XAF1 is one of the interferon-inducing genes, it upregulates caspase-3 $36 \mathrm{~h}$ after infection and mediates cell apoptosis(Junqi Huang et al., 2014; Long et al., 2013).

Besides, the intrinsic apoptotic pathway also plays an important role in this context. In HepG2 cells, DENV2 promoted changes in mitochondrial bioenergetics and caused typical apoptotic morphological changes, including cytoplasmic contraction, mitochondrial swelling and plasma membrane blistering(El-Bacha et al., 2007). In fact, changes in mitochondrial promote the activation of caspase- 9 , which then activates caspase-3, leading to DNA cleavage and apoptosis(Suwanmanee \& Luplertlop, 2017; Torrentes-Carvalho et al., 2009). Further results showed that in HepG2 cells, DENV2 initiated the unfolded protein response and the Noxa/PUMA stress response pathways(Thepparit et al., 2013). Moreover, a series of protein phosphorylation reactions are essential for inducing cell apoptosis. For example, DENV2 (strain 16881) increases the phosphorylation of JNK1/2 and p38MAPK through both intrinsic and extrinsic apoptotic pathways, leading to liver injury. The induced p53 phosphorylation and the decrease of anti-apoptotic Bcl-2 expression indicate the involvement of intrinsic apoptotic pathway, in which the induced expression of TNF- $\alpha$ and TRAIL may participate in the extrinsic apoptotic pathway(Sreekanth et al., 2017).

In addition, DENV2 can activate the transcription factor NF- $x \mathrm{~B}, \mathrm{NF}-\varkappa \mathrm{B}$ translocates to the nucleus to activate pro-inflammatory cytokine TNF- $\alpha$, and TNF- $\alpha$ binds to its transmembrane receptor TNFR to activate caspase-8 and dowmstrem effector caspase-3(Amar et al., 2011; Netsawang et al., 2014). Similarly, FasL interacts with Fas receptor present on immune cells to trigger apoptosis signals(H. Liao, Xu, \& Huang, 2010). In the TNF- $\alpha$ and FasL signaling pathways, the activation of enzyme phospholipase A2 (PLA2) seems to be essential for inducing apoptosis(Jäättelä, Benedict, Tewari, Shayman, \& Dixit, 1995; Nevalainen \& Losacker, 1997). This enzyme converts membrane phospholipids into arachidonic acid (AA), which is the main lipid mediator of several intracellular reactions(Axelrod, Burch, \& Jelsema, 1988; Malewicz, Parthasarathy, Jenkin, \& Baumann, 1981). AA stimulates the synthesis of NADPH oxidase to produce superoxide anions and other reactive oxygen species (ROS)(Jan et al., 2000), ROS can act as signal transducers and activate the expression of genes involved in apoptosis like NF- $x \mathrm{~B}$ (Xiao \& Ghosh, 2005). As well, excessive ROS will eventually initiate the mitochondrial apoptosis pathway(Olagnier et al., 2014). Moreover, a positive correlation between apoptosis, DNA damage and oxidative stress was found in PBMCs infected with DENV2, which paved the way for the determination of plausible immunopathological links contributing to disease pathogenesis. Besides, secondary messenger oxides like nitric oxide (NO) also mediates dengue-triggered apoptosis in a caspase dependent manner(C.-F. Lin et al., 2002). Beyond that, functional studies have shown that knocking down the sphingosine kinase2 (SPHK2) in HUH-7 cells infected with four serotypes of DENV reduce the activities of caspase-9 and caspase-3, suggesting that SPHK2 plays a role in promoting apoptosis through intrinsic pathway(A Morchang et al., 2017).

\section{Anti-apoptosis}

Although DENV2 has the function of inducing cell apoptosis, it also has the function of inhibiting cell apoptosis. Pena and Harris(José \& Eva, 2011) demonstrated that DENV2 manipulates the sequence of events to activate and inhibit the three different branches of UPR in a time-dependent manner, so that cells can adapt to infection stress, overcome translational inhibition, prevent premature apoptosis, and ultimately extend the life cycle of the virus. For instance, inhibition of XBP1 combined with DENV2 infection can lead to weakened ER expansion, enhanced cytopathic effects of the virus and increased levels of the apoptosis marker procaspase-3(C.-Y. Yu, Hsu, Liao, \& Lin, 2006). This further proves that the IRE1-XBP1 pathway 
can protect cells from apoptosis and reduce ER stress contributing to DENV pathogenesis, similar results have been observed in JEV-infected cells. Moreover, in mosquito cells, DENV-2 infection causes UPR to activate the PERK signaling pathway, thereby reducing the accumulation of ER stress, and activating antiapoptotic effects to help cells survive the continuous amplification of the virus(Hou et al., 2017). This phenomenon is very important for elucidating how mosquitoes can healthily serve as carriers of DENV and may-be other arboviruses. Another result showed that all the capsid proteins from 6 different flaviviruses (DENV, JEV, WNV, YFV, MVEV and SLEV) confer a protective effect on Fas-dependent apoptosis in a manner that increases phosphorylation of Akt thereby enhancing cell activity(Hart \& Vogt, 2011). Moreover, protein phosphatase 1, which is known to inactivate Akt, was identified as a DENV-C interacting protein, indicating that DENV-C activates Akt by sequestering phosphatases that downregulate phosphor-Akt(Airo et al., 2018).

Meanwhile, some factors play a role in inhibiting apoptosis in the process of DENV infection. DENV2-infected cells express high levels of calcium modulating cyclophilin-binding ligand (CMAL), a regulator of intracellular calcium levels(Bram \& Crabtree, 1994), the cells therefore have high cytosolic calcium concentration, which can help DENV2 to subvert apoptosis since it protects cells from mitochondrial damage(J. Li et al., 2012). Bcl-xL also plays a vital role in the survival of DENV, JEV and ZIKV infected cells, therefore Bcl-xL provides a novel antiviral target for inhibiting the propagation of flavivirus(Suzuki et al., 2018).

\subsubsection{Regulation of DENV proteins on apoptosis}

Limjindaporn et al.(Limjindaporn et al., 2007) confirmed that the DENV2 capsid protein (DENV2-C) physically interacts with death protein 6 (Daxx), a human death domain-associated protein, and the nuclear localization of DENV2-C is closely related to DAXX interaction and apoptosis induction, elucidating the pro-apoptotic function of DENV2-C(Netsawang et al., 2010). Moreover, DENV2-C promotes the release of NF- $x$ B by binding Daxx, which usually interacts with NF- $x$ B. Since NF- $x$ B can activate CD137 promoter, the interaction between CD137 ligand and CD137 eventually activates caspase cascades and apoptosis, indicating that NF- $\varkappa$ B signal contributes to DENV2-C-induced apoptosis(Nagila et al., 2011). Cell death gene RIPK2 (receptor-interacting serine/threonine protein kinase 2), is a key mediator of various stress responses, leading to the activation of NF- $\chi \mathrm{B}, \mathrm{MAPK}$ and caspases. The expression of RIPK2 contributes to apoptosis induced by capsid protein but only for DENV-2 and -4 serotypes(Atthapan Morchang et al., 2011). There is evidence that the M proteins of four DENV serotypes can trigger the intrinsic apoptosis pathway in host cells such as Neuro 2a and HepG2 cells, and the nine carboxy-terminal amino acids (residues M-32 to M-40) of M protein called ApoptoM is cytotoxic and directly involved. In addition, the M ectodomains of JEV, WNV and YFV also have pro-apoptotic effects, indicating that the M protein plays a key role in determining the fate of flavivirus-infected cells(Catteau et al., 2003). Another study found that DENV2-envelope protein domain III (DENV2-EIII) suppresses megakaryopoiesis by inducing apoptosis of differentiated Megakaryocytes (MKs), which is one of the causes of thrombocytopenia(G.-L. Lin et al., 2017). Therefore, DENV2-EIII can be used as a drug target to for the treatment of MKs deficiency and thrombocytopenia in severe dengue.

Subsequently, Ochoa et al.(Ochoa et al., 2009) found that human microvascular endothelial cells (HMEC-1) transfected with DENV2 serine protease NS3 or NS2B-NS3 complex can trigger apoptosis. Further study have shown that NS3 activates NF- $\chi \mathrm{B}$ by inducing $\mathrm{I} \chi \mathrm{B} \alpha / \mathrm{I} \varkappa \mathrm{B} \beta$ cleavage and activating $\mathrm{I} \chi \mathrm{B}$ kinase, which triggers the extrinsic apoptotic pathway(J.-C. Lin et al., 2014). Moreover, NS2B-NS3 caused a higher proportion of apoptosis, indicating that NS2B is an important cofactor for NS3 to induce apoptosis(Shafee \& AbuBakar, 2003). Interestingly, DENV-2 NS5 can also translocate into nucleus and interact with Daxx to further increase the production of RANTES. Therefore, NS5 may have a similar apoptosis-inducing function to DENV2-C, but this requires further experimental verification(Khunchai et al., 2012; Nagila et al., 2011).

\subsection{West Nile Virus}

\subsubsection{WNV regulation of apoptosis}

Although West Nile virus is not as versatile as dengue, it can trigger central nervous system (CNS) cell apoptosis, therefore establishing neuroinvasiveness. Neuro-2a cells (neuronal cells) and K562 (immune cells) 
infected by WNV show typical apoptotic characteristics, and the up-regulated Bax gene is involved(Parquet, Kumatori, Hasebe, Morita, \& Igarashi, 2001). Furthermore, WNV infection can induce T98G cells (brainderived) death through extrinsic and intrinsic apoptotic pathways, and caspase-3 dependent apoptosis contributes to the pathogenesis of fetal WNV encephalitis(Bimmi, David, \& Diamond, 2003; Kleinschmidt, Michaelis, Ogbomo, Doerr, \& Cinatl, 2007; Peng \& Wang, 2019; Samuel, Morrey, \& Diamond, 2007), which helps to clarify the pathogenesis of WNV-induced neuronal cell death and propose novel therapeutic targets that may restrict CNS damage. In Vero cells (epithelial cells), WNV can trigger the mitochondrial-mediated apoptosis pathway at low infectious doses $(\mathrm{MOI}<10)$, which is initiated by the release of Cyt-c and the formation of apoptosome. In contrast, cells infected with a higher load (MOI $>10)$ showed signs of necrosis(Chu $\& \mathrm{Ng}, 2003)$. The regulation of WNV and its protein on apoptosis is summarized in Table 2.

The ER stress is also involved, Medigeshi et al.(Medigeshi et al., 2007) found that the activation of two branches of UPR (ATF6 and PERK) after WNV infection can induce the production of proapoptotic CHOP and downstream apoptosis. However, $\mathrm{WNV}_{\mathrm{KUN}}$ (Kunjun strain) closes PERK pathway while activates the remaining two UPR (ATF6, IRE1) pathways in MEFs, further studies have found that these pathways increase cell viability and viral load by restricting apoptotic cell death(Ambrose \& Mackenzie, 2013). Surprisingly, after the WNV vector mosquitoes Culex pipiens pipiens (C.p.pipiens) are infected with WNV, a large number of midgut epithelial cells undergo apoptosis, which may affect virus transmission, disease epidemiology and viral evolution(Vaidyanathan \& Scott, 2006). Furthermore, in human and mouse cell culture, WNV affects non-coding microRNAs (miRNAs), among which microRNA Hs_154 is significantly upregulated. Two of its targets, CTCF (CCCTC-binding factor) and ECOP (EGFR-coamplified and overexpressed protein) are related to cell survival(Smith, Grey, Uhrlaub, Janko, \& Hirsch, 2012). The observation suggests that induction of Hs_154 expression can promote cell apoptosis, so this miRNA may become a candidate for therapeutic intervention.

\subsubsection{Regulation of WNV proteins on apoptosis}

Yang et al.(Joo-Sung et al., 2002) demonstrated for the first time that transfection of WNV-C in neuronal and non-neuronal cells can cause inflammation and apoptosis. Further studies have shown that WNV-C induces apoptosis by destroying mitochondrial membranes and activating caspase- 9 and caspase- 3 , and the 3 '-terminal region of the capsid protein is related to its apoptosis-inducing function. In addition, the WNV$\mathrm{C}$ protein phosphorylated by protein kinase $\mathrm{C}(\mathrm{PKC})$ can enhance its binding and nucleus co-localization with HDM2 protein, a p53 negative regulator, thereby stabilizing p53 and then inducing its apoptosis target protein Bax(Bhuvanakantham, Cheong, \& Ng, 2010; M. Yang et al., 2010). Despite the substantial evidence supporting the pro-apoptotic effect of capsid protein, Urbanowski et al.(Urbanowski \& Hobman, 2013) found that WNV-C inhibits cell apoptosis by activating Phosphatidylinositol-3-kinase (PI3K)-Akt pro-survival pathway in four mammalian cells (A549, HEK293T, Vero-76, BHK-21). The discrepancy between these reports may be due to the capsid protein containing an 18-amino-acid-residue signal peptide of prM in the earlier reports.

In 2006, Liu et al.(W. J. Liu et al., 2006) mutated the alanine at position 30 of the WNV-NS2A protein to proline $(\mathrm{A} 30 \mathrm{P})$ and found that the virulence of the virusviral was significantly weakened. Further, Melian et al. (Melian et al., 2013) used this mutant and wild strain to infect IFN- $\beta$-deficient cells, and found that the DNA degradation of the mutant group was reduced and the number of TUNEL-labeled positive cells decreased significantly, indicating that the WNV-NS2A protein plays a role in IFN-independent apoptosis. Moreover, the expression of NS2B-NS3 or NS3 protein, but not NS2B, can induce apoptosis. Further studies have showed that WNV-NS3 can trigger apoptosis mediated either individually or together by the caspases8 and -3 pathways, and the protease and helicase domains of NS3 protein are both essential for inducing apoptosis(Ramanathan et al., 2006). The thorough knowledge of the apoptotic pathways driven by NS2BNS3 and NS3 will undoubtedly provide valuable insights for development of novel therapeutics for this viral infection.

\subsection{Japanese Encephalitis Virus}




\subsubsection{JEV regulation of apoptosis}

Although the pathogenic mechanism of JEV is similar to that of WNV, JEV manipulates both intrinsic and extrinsic pathways to its advantage. The replication of JEV triggers a variety of cell apoptosis, as confirmed by DNA fragmentation ladder, nuclear condensation and TUNEL assay(C. L. Liao et al., 1997), and the stable expression of human Bcl-2 can delay JEV-induced apoptosis(C. L. Liao et al., 1998). Although JEV induces the classic intrinsic apoptotic pathway in N18 neuroblastoma cells, it activates both caspase-8 (part of the extrinsic pathway) and caspase-9 in a predominantly mitochondria-dependent pathway in MCF cells(Tsao et al., 2008). The regulation of JEV and its protein on apoptosis is summarized in Table 3.

Further, the apoptotic cell death induced by JEV depends on ER stress and the generation of ROS. Current research shows that these three proteins GRP78, mitochondrial protein Prohibitin (PHB), and heterogeneous nuclear ribonucleoprotein (hnRNPC) interact with JEV RNA, which in turn causes ER stress-induced apoptosis(Mukherjee et al., 2017). Another result shows that JEV-induced ER stress participates in the apoptosis process through p38-dependent and CHOP-mediated pathways(Hong-Lin, Ching-Len, \& Yi-Ling, 2002; Sankar, Utsav, \& Sudhanshu, 2014), and the IRE1/JNK pathway of ER stress is also an important mechanism for JEV to induce apoptosis(M. Huang et al., 2016). Even replication-incompetent strain (UV-JEV) retain their ability to kill neuronal cells by triggering a ROS-dependent, partly NF- $x \mathrm{~B}-$ mediated pathway(R.-J. Lin, Liao, \& Lin, 2004).

In addition, Guo et al.(Guo et al., 2018) found that JEV induces apoptosis by inhibiting the STAT3-FoxoBcl-6/p21 pathway, indicating that this pathway has a certain pro-survival effect, which provides novel insights into JEV-induced encephalitis. Followed, significant up-regulation of Bax, Bid, Fas , FasL and down-regulation of IGFBP-2, p27, p53 were respectively observed in JEV infected cells with 0.5 and 10 MOI compared to uninfected cells(Al-Obaidi et al., 2017). As a result, in the case of low MOI, expression of proteins involved in inducing apoptosis indicates that the immune system has played a protective role of in preventing the virus from completing its replication and producing infectious progeny viruses. While at high MOI, most of proapoptotic proteins are reduced, which means that the virus has capacity to disable host cell apoptotic mechanisms that may be obligatory for virus life cycle completion.

\subsubsection{Regulation of JEV proteins on apoptosis}

Firstly, E protein of JEV can induce apoptosis of HepG2 and Vero cells(S-O, T-J, Stone, C-H, \& J-J, 2006). Further studies have shown that JEV NS3 protein, as well as NS3 helicase and protease domains induce apoptosis through caspase-dependent (caspase-9/-3) and -independent pathways(Yiang et al., 2013). Research by Yang et al.(T. C. Yang et al., 2009) showed that JEV NS2B-NS3 induces the reduction of MMP and the release of Cyt-c, leading to mitochondrial-mediated apoptosis. Moreover, ROS-mediated activation of ASK1-p38 MAPK signaling pathway is also related to NS2B-NS3 induced apoptosis. Recently results show that JEV-NS5 not only participates in type I IFN antagonism, but also plays an anti-apoptotic effect by preventing IFN- $\beta$-induced p38 MAPK/STAT1-mediated apoptosis(Weng et al., 2018).

\subsection{Zika Virus}

\subsubsection{ZIKV regulation of apoptosis}

It is worth noting that ZIKV infection can induce apoptosis through caspase-3-mediated pathways both in vitro and in vivo (J. Chen et al., 2017; W.-C. Huang, Abraham, Shim, Choe, \& Page, 2016; M.-Y. Lin et al., 2017; Yan et al., 2019). Further, a variety of apoptosis markers were detected in neural parenchyma isolated from clinical cases, including FASL, FAS, Bax and caspase-3(de Sousa et al., 2018). And numerous reports show that neural cell apoptosis increases after ZIKV infection(Ghouzzi et al., 2017; W.-C. Huang et al., 2016; C. Li et al., 2016; Qian et al., 2016; Souza et al., 2016). For example, ZIKV preferentially induces apoptosis of neuro progenitor cells (NPCs), which is confirmed by the activation of caspases-3/7, -8 and -9 , as well as ultrastructural and flow cytometry analysis(Jungmann, Pires, \& Araujo Júnior, 2017; Martinot et al., 2018; Tang et al., 2016). In human neural stem cells (hNSCs), the cleavage of PARP and caspase-3 are participated in the apoptosis process(Devhare, Meyer, Steele, Ray, \& Ray, 2017). These results contribute 
to ZIKV-induced abnormal development of the nervous system. The regulation of ZIKV and its protein on apoptosis is summarized in Table 4.

In addition to neural cells, many other cell types can also cause extensive apoptosis after ZIKV infection, such as HEK293 (embryonic cells)(H. Liu et al., 2019), GSCs (glioma stem cells)(Q. Chen et al., 2018), Vero and A549(McFadden et al., 2018; Park et al., 2019) (epithelial cells) and hepatocyte cells lines (HuH7.5 and HepG2)(Sherman et al., 2019). Another result suggests that ZIKV induces renal apoptosis by downregulating expression of $\mathrm{Bcl}-2$ and the up-regulating the expression of cleaved caspase- 3 and PARP(T. Liu et al., 2019), which is similar to that observed in neural cells. Interestingly, ZIKV infection is related to proinflammatory cytokine expression and apoptosis in placental explants, thus we propose that human placental explants can be used as a model for studying ZIKV infection in vitro (Ribeiro et al., 2018).

The tumor suppressor protein p53 is also involved in ZIKV-mediated apoptosis, as the inhibition of p53 limits ZIKV-induced apoptosis in neural progenitors(Zhang et al., 2016). Since p53 can activate several pro-apoptotic genes such as Bax, Noxa and Puma, and inhibit anti-apoptotic gene survivin, leading to the activation of apoptosis. The physiological and metabolic changes in the ER after ZIKV infection lead to the activation of ER stress, and continuous ER stress then triggers apoptosis via upregulation of CHOP in vivo (Gladwyn-Ng et al., 2018; Oyarzún-Arrau, Alonso-Palomares, Valiente-Echeverría, Osorio, \& Soto-Rifo, 2020; Tan et al., 2018).

\subsubsection{Regulation of ZIKV proteins on apoptosis}

Newly results indicate that ZIKV-C protein interacts with mouse double-minute-2 homolog (MDM2), which is involved in the p53-mediated apoptosis pathway, activating the death of infected neural cells(Teng et al., 2017). Further studies have shown that the nuclear localization of ZIKA-C is related to ribosomal stress (RS) and apoptosis, and the $22 \mathrm{C}$-terminal residues of ZIKV-C are essential for nuclear localization, RS and apoptosis(Slomnicki et al., 2017). Moreover, DENV2-C was found to have a similar apoptosis-inducing mechanism with ZIKA-C. ZIKV-prM protein can induce apoptotic cell death, and the Pr region located on the N-terminal side of prM protein is responsible for prM-induced apoptosis(G. Li et al., 2019). In addition, E protein of ZIKV can induce apoptosis in differentiating hNSC(Bhagat et al., 2018). ZIKV-E can also inhibit the proliferation of PC12 cells, triggere G2/M cell cycle arrest and apoptosis, further analysis showed that ZIKV-E caused apoptosis via intrinsic cell death pathway that was dependent on caspase- $9 / 3$ activation and accompanied by an increase in the ratio of Bax to Bcl-2(J. Liu et al., 2018).

\subsection{Other Flavivirus}

YFV infection increases the expression of caspase-3 and caspase-7, and ultimately leads to apoptosis(Holanda, Casseb, Quaresma, Vasconcelos, \& Cruz, 2019). Besides, YFV infection can regulate the expression of various cytokines such as TGF- $\beta$, TNF- $\alpha$, IFN- $\beta$ and IFN- $\gamma$, which are participated in viral infection-induced apoptosis(Quaresma et al., 2006). Furthermore, the tick-borne flaviviruses LIV and TBEV can induce increased expression of apoptosis pathway related genes after infectionI. ricinus cells(Mansfield et al., 2017). Langat virus can induce neural and nonneural cell apoptosi, further experiments showed that P35 protein can inhibit a variety of caspases, while LGTV E protein can activate caspase-3 by inhibiting the activity of P35 protein, thereby reducing cell viability and inducing apoptosis(Prikhod'Ko, Prikhod'Ko, Cohen, \& Pletnev, 2001). The regulation of other flavivirus on apoptosis is summarized in Table 5.

\section{Conclusion}

This review is the first glimpse of flavivirus-induced apoptosis based on a wide array of reported work concerning flavivirus infection. It summarizes the current findings of flavivirus regulation of cell apoptosis, including a vast panel of distinct pro-apoptotic and anti-apoptotic mechanisms. The aftermath of virus invasion depend on the initial dose and cell type, and it can also switch to different mechanisms to exert its pathogenic effects in different cells. Taking the above viewpoints into consideration will help us better understand the mechanism of flavivirus-induced apoptosis and open a new gate for further research on the pathogenesis of flavivirus. And more emphasis needs to be put on studying the signaling pathways by which 
viruses regulate cell survival pathways. Future research should focus on the function of individual viral proteins, the host-virus interaction between viruses and cellular proteins, and the regulation of non-coding RNAs in viral infections.

\section{Abbreviations:}

DENV, Dengue virus; JEV, Japanese Encephalitis Virus; WNV, West Nile virus; ZIKV, Zika virus; YFV, Yellow fever virus; TBEV, tick-borne Encephalitis virus; ORF, open reading frame; ER, endoplasmic reticulum; RdRp, RNA-dependent RNA polymerase; Cyt-c, cytochrome c; PTP, permeability transition pore; MMP, mitochondrial membrane potential; IAPs, inhibitors of apoptotic protein; AIF, apoptosis inducing factor; UPR, unfolded protein response; IRE1, inositol requiring protein-1; PERK, protein kinase RNA-like ER kinase; ATF6, activating transcription factor-6; TRAF2, TNF receptor-associated factor 2; ASK1, apoptosis signaling kinase 1; eIF2 $\alpha$, eukaryotic translation initiation factor $2 \alpha$ ATF4, activating transcription factor 4; TNF, tumor necrosis factor; DD, death domain; FasL, Fas ligand; FADD, Fas-associated protein with death domain; DED, death effector domain; DISC, death-inducing signaling complex; RIP1, receptor-interacting protein kinase; Daxx, death protein 6; RIPK2, receptor-interacting serine/threonine protein kinase 2; CNS, central nervous system; MDM2, mouse double-minute-2 homolog; RS, ribosomal stress.

\section{Author Contributions}

YP contributed ideas for the review and wrote the manuscript and produced the figures; AC, MW, ZY and RJ edited and revised the manuscript.

\section{Conflict of Interest}

The authors declare no conflict of interest.

\section{Funding}

This work was supported by the National Natural Science Foundation of China (31872475), Sichuan Veterinary Medicine and Drug Innovation Group of China Agricultural Research System (CARS-SVDIP) and China Agricultural Research System (CARS-42-17).

\section{Acknowledgements}

We apologize to the authors of articles reporting relevant research that were not cited in this manuscript due to limited space.

\section{References}

Airo, A. M., Urbanowski, M. D., Lopez-Orozco, J., You, J. H., Skene-Arnold, T. D., Holmes, C., . . . Hobman, T. C. (2018). Expression of flavivirus capsids enhance the cellular environment for viral replication by activating Akt-signalling pathways. Virology, 516 , 147-157. doi:10.1016/j.virol.2018.01.009

Al-Obaidi, M. M. J., Bahadoran, A., Har, L. S., Mui, W. S., Rajarajeswaran, J., Zandi, K., . . . Sekaran, S. D. (2017). Japanese encephalitis virus disrupts blood-brain barrier and modulates apoptosis proteins in THBMEC cells. Virus Research, 233 , 17-28. doi:10.1016/j.virusres.2017.02.012

Amar, N., Janjuree, N., Chatchawan, S., Sansanee, N., Atthapan, M., Umpa, Y., . . . Pa-Thai, Y. (2011). Role of CD137 signaling in dengue virus-mediated apoptosis. Biochemical and Biophysical Research Communications, 410 (3), 428-433.

Ambrose, R. L., \& Mackenzie, J. M. (2013). ATF6 signaling is required for efficient West Nile virus replication by promoting cell survival and inhibition of innate immune responses. Journal of Virology, 87 (4), 2206-2214. doi:10.1128/JVI.02097-12

Ashkenazi, A. (2008). Targeting the extrinsic apoptosis pathway in cancer. Cytokine and Growth Factor Reviews, 19 (3-4), 325-331. doi:10.1016/j.cytogfr.2008.04.001 
Ashkenazi, A., \& Salvesen, G. (2014). Regulated cell death: signaling and mechanisms. Annual Review of Cell and Developmental Biology, 30 , 337-356. doi:10.1146/annurev-cellbio-100913-013226

Avirutnan, P., ., Malasit, P., ., Seliger, B., ., Bhakdi, S., ., \& Husmann, M., . (1998). Dengue virus infection of human endothelial cells leads to chemokine production, complement activation, and apoptosis. Journal of Immunology, 161 (11), 6338-6346.

Axelrod, J., Burch, R. M., \& Jelsema, C. L. (1988). Receptor-mediated activation of phospholipase A2 via GTP-binding proteins: arachidonic acid and its metabolites as second messengers. Trends in Neurosciences, 11 (3), 117-123.

Benedict, C. A., Norris, P. S., \& Ware, C. F. (2002). To kill or be killed: viral evasion of apoptosis.Nature Immunology, 3 (11), 1013-1018.

Bhagat, R., Prajapati, B., Narwal, S., Agnihotri, N., Adlakha, Y. K., Sen, J., . . . Seth, P. (2018). Zika virus $\mathrm{E}$ protein alters the properties of human fetal neural stem cells by modulating microRNA circuitry. Cell Death and Differentiation, 25 (10), 1837-1854. doi:10.1038/s41418-018-0163-y

Bhuvanakantham, R., Cheong, Y. K., \& Ng, M. L. (2010). West Nile virus capsid protein interaction with importin and HDM2 protein is regulated by protein kinase C-mediated phosphorylation. Microbes $\mathbb{E}$ Infection, 12 (8), 615-625.

Bimmi, S., David, G., \& Diamond, M. S. (2003). Infection and injury of neurons by West Nile encephalitis virus. Journal of Virology, 77 (24), 13203.

Borner, C., \& Andrews, D. W. (2014). The apoptotic pore on mitochondria: are we breaking through or still stuck? Cell Death and Differentiation, 21 (2), 187-191. doi:10.1038/cdd.2013.169

Bram, R. J., \& Crabtree, G. R. (1994). Calcium signalling in T cells stimulated by a cyclophilin B-binding protein. Nature, 371 (6495), 355-358.

Bressanelli, S., Stiasny, K., Allison, S. L., Stura, E. A., Duquerroy, S., Lescar, J., . . . Rey, F. A. (2004). Structure of a flavivirus envelope glycoprotein in its low-pH-induced membrane fusion conformation. EMBO Journal, 23 (4), 728-738. doi:10.1038/sj.emboj.7600064

Brinton, M. A. (2002). The molecular biology of West Nile Virus: a new invader of the western hemisphere. Annual Review of Microbiology, $56,371-402$.

Catteau, A., Kalinina, O., Wagner, M. C., Deubel, V., Courageot, M. P., \& Desprès, P. (2003). Dengue virus M protein contains a proapoptotic sequence referred to as ApoptoM.Journal of General Virology, 84 (Pt 10), 2781.

Chen, J., Yang, Y. F., Chen, J., Zhou, X., Dong, Z., Chen, T., . . Zhu, T. (2017). Zika virus infects renal proximal tubular epithelial cells with prolonged persistency and cytopathic effects. Emerg Microbes Infect, 6 (8), e77. doi:10.1038/emi.2017.67

Chen, Q., Wu, J., Ye, Q., Ma, F., Zhu, Q., Wu, Y., . . Qin, C.-F. (2018). Treatment of Human Glioblastoma with a Live Attenuated Zika Virus Vaccine Candidate.mBio, 9 (5). doi:10.1128/mBio.01683-18

Chu, J. J. H., \& Ng, M. L. (2003). The mechanism of cell death during West Nile virus infection is dependent on initial infectious dose. Journal of General Virology, 84 (Pt 12), 3305.

Courageot, M.-P., Catteau, A., \& Desprès, P. (2003). Mechanisms of dengue virus-induced cell death.Advances in Virus Research, 60 , 157-186.

de Sousa, J. R., Azevedo, R. S. S., Martins Filho, A. J., Araujo, M. T. F., Moutinho, E. R. C., Baldez Vasconcelos, B. C., . . . Vasconcelos, P. F. C. (2018). Correlation between Apoptosis and in Situ Immune Response in Fatal Cases of Microcephaly Caused by Zika Virus. The American Journal of Pathology, 188 (11), 2644-2652. doi:10.1016/j.ajpath.2018.07.009 
Desprès, P., ., Flamand, M., ., Ceccaldi, P. E., \& Deubel, V., . (1996). Human isolates of dengue type 1 virus induce apoptosis in mouse neuroblastoma cells. Journal of Virology, 70 (6), 4090-4096.

Devhare, P., Meyer, K., Steele, R., Ray, R. B., \& Ray, R. (2017). Zika virus infection dysregulates human neural stem cell growth and inhibits differentiation into neuroprogenitor cells. Cell Death 83 Disease, 8 (10), e3106. doi:10.1038/cddis.2017.517

El-Bacha, T., Midlej, V., Pereira da Silva, A. P., Silva da Costa, L., Benchimol, M., Galina, A., \& Da Poian, A. T. (2007). Mitochondrial and bioenergetic dysfunction in human hepatic cells infected with dengue 2 virus. Biochimica et Biophysica Acta, 1772 (10), 1158-1166.

Galluzzi, L., Kepp, O., \& Kroemer, G. (2012). Mitochondria: master regulators of danger signalling.Nature reviews. Molecular cell biology, 13 (12), 780-788. doi:10.1038/nrm3479

Garrido, C., Galluzzi, L., Brunet, M., Puig, P. E., Didelot, C., \& Kroemer, G. (2006). Mechanisms of cytochrome c release from mitochondria. Cell Death and Differentiation, 13 (9), 1423-1433.

Ghouzzi, V. E., Bianchi, F. T., Molineris, I., Mounce, B. C., Berto, G. E., Rak, M., . . Di Cunto, F. (2017). ZIKA virus elicits P53 activation and genotoxic stress in human neural progenitors similar to mutations involved in severe forms of genetic microcephaly and p53. Cell Death 85 Disease, 8 (1), e2567. doi:10.1038/cddis.2016.446

Gladwyn-Ng, I., Cordón-Barris, L., Alfano, C., Creppe, C., Couderc, T., Morelli, G., . . Nguyen, L. (2018). Stress-induced unfolded protein response contributes to Zika virus-associated microcephaly. Nature Neuroscience, 21 (1), 63-71. doi:10.1038/s41593-017-0038-4

Guo, F., Yu, X., Xu, A., Xu, J., Wang, Q., Guo, Y., . . . Kong, L. (2018). Japanese encephalitis virus induces apoptosis by inhibiting Foxo signaling pathway. Veterinary Microbiology, 220 , 73-82. doi:10.1016/j.vetmic.2018.05.008

Hart, J. R., \& Vogt, P. K. (2011). Phosphorylation of AKT: a mutational analysis. Oncotarget, 2 (6), 467-476.

Hirsch, I., Weiwad, M., Prell, E., \& Ferrari, D. M. (2014). ERp29 deficiency affects sensitivity to apoptosis via impairment of the ATF6-CHOP pathway of stress response.Apoptosis : an international journal on programmed cell death, 19 (5), 801-815. doi:10.1007/s10495-013-0961-0

Holanda, G. M., Casseb, S. M. M., Quaresma, J. A. S., Vasconcelos, P. F. C., \& Cruz, A. C. R. (2019). Yellow fever virus modulates cytokine mRNA expression and induces activation of caspase $3 / 7$ in the human hepatocarcinoma cell line HepG2.Archives of Virology, 164 (4), 1187-1192. doi:10.1007/s00705-019-04171-7

Hong-Lin, S., Ching-Len, L., \& Yi-Ling, L. (2002). Japanese encephalitis virus infection initiates endoplasmic reticulum stress and an unfolded protein response. Journal of Virology, 76 (9), 4162-4171.

Hou, J.-N., Chen, T.-H., Chiang, Y.-H., Peng, J.-Y., Yang, T.-H., Cheng, C.-C., . . Chen, W.-J. (2017). PERK Signal-Modulated Protein Translation Promotes the Survivability of Dengue 2 Virus-Infected Mosquito Cells and Extends Viral Replication.Viruses, 9 (9). doi:10.3390/v9090262

Huang, J., Haoyue, S., Renyong, J., Mingshu, W., Shun, C., Dekang, Z., . . . Viruses, W. Y. J. (2018). Oral Vaccination with a DNA Vaccine Encoding Capsid Protein of Duck Tembusu Virus Induces Protection Immunity. Viruses, 10 (4), 180.

Huang, J., Li, Y., Qi, Y., Zhang, Y., Zhang, L., Wang, Z., . . Gui, L. (2014). Coordinated regulation of autophagy and apoptosis determines endothelial cell fate during Dengue virus type 2 infection. Molecular and Cellular Biochemistry, 397 (1-2), 157-165. doi:10.1007/s11010-014-2183-3

Huang, K., Zhang, J., O’Neill, K. L., Gurumurthy, C. B., Quadros, R. M., Tu, Y., \& Luo, X. (2016). Cleavage by Caspase 8 and Mitochondrial Membrane Association Activate the BH3-only Protein Bid during TRAILinduced Apoptosis. The Journal of biological chemistry, 291 (22), 11843-11851. doi:10.1074/jbc.M115.711051 
Huang, M., Xu, A., Wu, X., Zhang, Y., Guo, Y., Guo, F., . . Kong, L. (2016). Japanese encephalitis virus induces apoptosis by the IRE1/JNK pathway of ER stress response in BHK-21 cells. Archives of Virology, 161 (3), 699-703.

Huang, W.-C., Abraham, R., Shim, B.-S., Choe, H., \& Page, D. T. (2016). Zika virus infection during the period of maximal brain growth causes microcephaly and corticospinal neuron apoptosis in wild type mice. Scientific Reports, 6 , 34793. doi:10.1038/srep34793

Jäättelä, M., Benedict, M., Tewari, M., Shayman, J. A., \& Dixit, V. M. (1995). Bcl-x and Bcl-2 inhibit TNF and Fas-induced apoptosis and activation of phospholipase A2 in breast carcinoma cells. Oncogene, 10 (12), 2297-2305.

Jan, J. T., Chen, B. H., Ma, S. H., Liu, C. I., Tsai, H. P., Wu, H. C., . . Shaio, M. F. (2000). Potential dengue virus-triggered apoptotic pathway in human neuroblastoma cells: arachidonic acid, superoxide anion, and NF-kappaB are sequentially involved. Journal of Virology, 74 (18), 8680-8691.

Jang, D. S., Penthala, N. R., Apostolov, E. O., Wang, X., Crooks, P. A., \& Basnakian, A. G. (2015). Novel cytoprotective inhibitors for apoptotic endonuclease G. DNA and Cell Biology, 34 (2). doi:10.1089/dna.2014.2530

Joo-Sung, Y., Ramanathan, M. P., Karuppiah, M., Choo, A. Y., Sung-Ha, J., Qian-Chun, Y., ... Kesen, D. (2002). Induction of inflammation by West Nile virus capsid through the caspase-9 apoptotic pathway. Emerging Infectious Diseases, 8 (12), 1379-1384.

José, P. A., \& Eva, H. (2011). Dengue virus modulates the unfolded protein response in a time-dependent manner. Journal of Biological Chemistry, 286 (16), 14226.

Joza, N., Susin, S. A., Daugas, E., Stanford, W. L., Cho, S. K., Li, C. Y., . . Penninger, J. M. (2001). Essential role of the mitochondrial apoptosis-inducing factor in programmed cell death. Nature, 410 (6828), 549-554.

Jungmann, P., Pires, P., \& Araujo Júnior, E. (2017). Early insights into Zika's microcephaly physiopathology from the epicenter of the outbreak: teratogenic apoptosis in the central nervous system. Acta Obstetricia et Gynecologica Scandinavica, 96 (9), 1039-1044. doi:10.1111/aogs.13184

Kennedy, P. G. E. (2015). Viruses, apoptosis, and neuroinflammation-a double-edged sword. Journal of Neurovirology, 21 (1), 1-7. doi:10.1007/s13365-014-0306-y

Khunchai, S., Junking, M., Suttitheptumrong, A., Yasamut, U., Sawasdee, N., Netsawang, J., . . - Limjindaporn, T. (2012). Interaction of dengue virus nonstructural protein 5 with Daxx modulates RANTES production. Biochemical and Biophysical Research Communications, 423 (2), 398-403. doi:10.1016/j.bbrc.2012.05.137

Kilbride, S. M., \& Prehn, J. H. M. (2013). Central roles of apoptotic proteins in mitochondrial function. Oncogene, 32 (22), 2703-2711. doi:10.1038/onc.2012.348

Kischkel, F. C., Hellbardt, S., Behrmann, I., Germer, M., Pawlita, M., Krammer, P. H., \& Peter, M. E. (1995). Cytotoxicity-dependent APO-1 (Fas/CD95)-associated proteins form a death-inducing signaling complex (DISC) with the receptor. The EMBO journal, 14 (22), 5579-5588.

Kleinschmidt, M. C., Michaelis, M., Ogbomo, H., Doerr, H.-W., \& Cinatl, J. (2007). Inhibition of apoptosis prevents West Nile virus induced cell death. BMC Microbiology, 7 , 49.

Li, C., Xu, D., Ye, Q., Hong, S., Jiang, Y., Liu, X., . . Xu, Z. (2016). Zika Virus Disrupts Neural Progenitor Development and Leads to Microcephaly in Mice. Cell stem cell, 19 (5), 672. doi:10.1016/j.stem.2016.10.017

Li, G., Bos, S., Tsetsarkin, K. A., Pletnev, A. G., Desprès, P., Gadea, G., \& Zhao, R. Y. (2019). The Roles of prM-E Proteins in Historical and Epidemic Zika Virus-mediated Infection and Neurocytotoxicity. Viruses, 11 (2). doi:10.3390/v11020157 
Li, J., Huang, R., Liao, W., Chen, Z., Zhang, S., \& Huang, R. (2012). Dengue virus utilizes calcium modulating cyclophilin-binding ligand to subvert apoptosis.Biochemical and Biophysical Research Communications, 418 (4), 622-627. doi:10.1016/j.bbrc.2012.01.050

Li, L., Lok, S.-M., Yu, I. M., Zhang, Y., Kuhn, R. J., Chen, J., \& Rossmann, M. G. (2008). The flavivirus precursor membrane-envelope protein complex: structure and maturation.Science (New York, N.Y.), 319 (5871), 1830-1834. doi:10.1126/science.1153263

Liao, C. L., Lin, Y. L., Shen, S. C., Shen, J. Y., Su, H. L., Huang, Y. L., . . Chen, L. K. (1998). Antiapoptotic but not antiviral function of human bcl-2 assists establishment of Japanese encephalitis virus persistence in cultured cells. Journal of Virology, 72 (12), 9844-9854.

Liao, C. L., Lin, Y. L., Wang, J. J., Huang, Y. L., Yeh, C. T., Ma, S. H., \& Chen, L. K. (1997). Effect of enforced expression of human bcl-2 on Japanese encephalitis virus-induced apoptosis in cultured cells. Journal of Virology, 71 (8), 5963-5971.

Liao, H., Xu, J., \& Huang, J. (2010). FasL/Fas pathway is involved in dengue virus induced apoptosis of the vascular endothelial cells. Journal of Medical Virology, 82 (8), 1392-1399. doi:10.1002/jmv.21815

Limjindaporn, T., Netsawang, J., Noisakran, S., Thiemmeca, S., Wongwiwat, W., Sudsaward, S., . . Malasit, P. (2007). Sensitization to Fas-mediated apoptosis by dengue virus capsid protein. Biochemical and Biophysical Research Communications, 362 (2), 334-339.

Limonta, D., Capó, V., Torres, G., Pérez, A. B., \& Guzmán, M. G. (2007). Apoptosis in tissues from fatal dengue shock syndrome. Journal of clinical virology : the official publication of the Pan American Society for Clinical Virology, 40 (1), 50-54.

Lin, C.-F., Lei, H.-Y., Shiau, A.-L., Liu, H.-S., Yeh, T.-M., Chen, S.-H., . . Lin, Y.-S. (2002). Endothelial cell apoptosis induced by antibodies against dengue virus nonstructural protein 1 via production of nitric oxide. Journal of immunology (Baltimore, Md. : 1950), 169 (2), 657-664.

Lin, G.-L., Chang, H.-H., Lien, T.-S., Chen, P.-K., Chan, H., Su, M.-T., . . Sun, D.-S. (2017). Suppressive effect of dengue virus envelope protein domain III on megakaryopoiesis. Virulence, 8 (8), 1719-1731. doi:10.1080/21505594.2017.1343769

Lin, J.-C., Lin, S.-C., Chen, W.-Y., Yen, Y.-T., Lai, C.-W., Tao, M.-H., . . . Wu-Hsieh, B. A. (2014). Dengue viral protease interaction with $\mathrm{NF}-\varkappa \mathrm{B}$ inhibitor $\alpha / \beta$ results in endothelial cell apoptosis and hemorrhage development. Journal of immunology (Baltimore, Md. : 1950), 193 (3), 1258-1267. doi:10.4049/jimmunol.1302675

Lin, M.-Y., Wang, Y.-L., Wu, W.-L., Wolseley, V., Tsai, M.-T., Radic, V., . . . Huang, I. C. (2017). Zika Virus Infects Intermediate Progenitor Cells and Post-mitotic Committed Neurons in Human Fetal Brain Tissues. Scientific Reports, 7 (1), 14883. doi:10.1038/s41598-017-13980-2

Lin, R.-J., Liao, C.-L., \& Lin, Y.-L. (2004). Replication-incompetent virions of Japanese encephalitis virus trigger neuronal cell death by oxidative stress in a culture system. The Journal of general virology, 85 (Pt 2), 521-533. doi:10.1099/vir.0.19496-0

Liu, H., Liao, H.-M., Li, B., Tsai, S., Hung, G.-C., \& Lo, S.-C. (2019). Comparative Genomics, Infectivity and Cytopathogenicity of American Isolates of Zika Virus that Developed Persistent Infections in Human Embryonic Kidney (HEK293) Cells.International Journal of Molecular Sciences, 20 (12). doi:10.3390/ijms20123035

Liu, J., Li, Q., Li, X., Qiu, Z., Li, A., Liang, W., . . . Li, H. (2018). Zika Virus Envelope Protein induces G2/M Cell Cycle Arrest and Apoptosis via an Intrinsic Cell Death Signaling Pathway in Neuroendocrine PC12 Cells. International Journal of Biological Sciences, 14 (9), 1099-1108. doi:10.7150/ijbs.26400

Liu, T., Tang, L., Tang, H., Pu, J., Gong, S., Fang, D., . . . Huang, X. (2019). Zika Virus Infection Induces Acute Kidney Injury Through Activating NLRP3 Inflammasome Via Suppressing Bcl-2. Frontiers 
in Immunology, 10 , 1925. doi:10.3389/fimmu.2019.01925

Liu, W. J., Wang, X. J., Clark, D. C., Lobigs, M., Hall, R. A., \& Khromykh, A. A. (2006). A Single Amino Acid Substitution in the West Nile Virus Nonstructural Protein NS2A Disables Its Ability To Inhibit Alpha/Beta Interferon Induction and Attenuates Virus Virulence in Mice. Journal of Virology, 80 (5), 2396-2404. doi:10.1128/jvi.80.5.2396-2404.2006

Liu, X., Kim, C. N., Yang, J., Jemmerson, R., \& Wang, X. (1996). Induction of apoptotic program in cell-free extracts: requirement for dATP and cytochrome c. Cell, 86 (1), 147-157.

Locksley, R. M., Killeen, N., \& Lenardo, M. J. (2001). The TNF and TNF receptor superfamilies: integrating mammalian biology. Cell, 104 (4), 487-501.

Long, X., Li, Y., Qi, Y., Xu, J., Wang, Z., Zhang, X., . . . Huang, J. (2013). XAF1 contributes to dengue virus-induced apoptosis in vascular endothelial cells. FASEB journal : official publication of the Federation of American Societies for Experimental Biology, 27 (3), 1062-1073. doi:10.1096/fj.12-213967

Lorenz, I. C., Kartenbeck, J., Mezzacasa, A., Allison, S. L., Heinz, F. X., \& Helenius, A. (2003). Intracellular assembly and secretion of recombinant subviral particles from tick-borne encephalitis virus. Journal of Virology, 77 (7), 4370-4382.

Mackenzie, J. M., \& Westaway, E. G. (2001). Assembly and maturation of the flavivirus Kunjin virus appear to occur in the rough endoplasmic reticulum and along the secretory pathway, respectively. Journal of Virology, 75 (22), 10787-10799.

Mahmood, Z., \& Shukla, Y. (2010). Death receptors: targets for cancer therapy. Experimental Cell Research, 316 (6), 887-899. doi:10.1016/j.yexcr.2009.12.011

Malewicz, B., Parthasarathy, S., Jenkin, H. M., \& Baumann, W. J. (1981). Rapid phospholipase A2 stimulation and diacylglycerol cholinephosphotransferase inhibition in baby hamster kidney cells during initiation of dengue virus infection. Biochemical and Biophysical Research Communications, 101 (2), 404-410.

Mansfield, K. L., Cook, C., Ellis, R. J., Bell-Sakyi, L., Johnson, N., Alberdi, P., . . . Fooks, A. R. (2017). Tick-borne pathogens induce differential expression of genes promoting cell survival and host resistance in Ixodes ricinus cells.Parasites \& vectors, 10 (1), 81. doi:10.1186/s13071-017-2011-1

Marianneau, P., ., Cardona, A., ., Edelman, L., ., Deubel, V., ., \& Desprès, P., . (1997). Dengue virus replication in human hepatoma cells activates NF-kappaB which in turn induces apoptotic cell death. Journal of Virology, 71 (4), 3244-3249.

Martinot, A. J., Abbink, P., Afacan, O., Prohl, A. K., Bronson, R., Hecht, J. L., . . . Barouch, D. H. (2018). Fetal Neuropathology in Zika Virus-Infected Pregnant Female Rhesus Monkeys. Cell, 173 (5). doi:10.1016/j.cell.2018.03.019

McFadden, M. J., Mitchell-Dick, A., Vazquez, C., Roder, A. E., Labagnara, K. F., McMahon, J. J., . . . Horner, S. M. (2018). A Fluorescent Cell-Based System for Imaging Zika Virus Infection in Real-Time. Viruses, 10 (2). doi:10.3390/v10020095

Medigeshi, G. R., Lancaster, A. M., Hirsch, A. J., Thomas, B., W Ian, L., Victor, D., . . Nelson, J. A. (2007). West Nile virus infection activates the unfolded protein response, leading to CHOP induction and apoptosis. Journal of Virology, 81 (20), 10849-10860.

Melian, E. B., Edmonds, J. H., Nagasaki, T. K., Hinzman, E., Floden, N., \& Khromykh, A. A. (2013). West Nile virus NS2A protein facilitates virus-induced apoptosis independently of interferon response. Journal of General Virology, 94 (Pt_2), 308-313.

Morchang, A., Rch, L., Yenchitsomanus, P. T., Sreekanth, G. P., Noisakran, S., Chu, J., \& Limjindaporn, T. (2017). RNAi screen reveals a role of SPHK2 in dengue virus-mediated apoptosis in hepatic cell lines. PloS One, 12 (11), e0188121. 
Morchang, A., Yasamut, U., Netsawang, J., Noisakran, S., Wongwiwat, W., Songprakhon, P., . . . Limjindaporn, T. (2011). Cell death gene expression profile: role of RIPK2 in dengue virus-mediated apoptosis. Virus Research, 156 (1-2), 25-34. doi:10.1016/j.virusres.2010.12.012

Morishima, N., Nakanishi, K., \& Nakano, A. (2011). Activating transcription factor-6 (ATF6) mediates apoptosis with reduction of myeloid cell leukemia sequence 1 (Mcl-1) protein via induction of WW domain binding protein 1. The Journal of biological chemistry, 286 (40), 35227-35235. doi:10.1074/jbc.M111.233502

Mukherjee, S., Singh, N., Sengupta, N., Fatima, M., Seth, P., Mahadevan, A., . . Basu, A. (2017). Japanese encephalitis virus induces human neural stem/progenitor cell death by elevating GRP78, PHB and hnRNPC through ER stress. Cell Death $\mathcal{G}$ Disease, 8 (1), e2556. doi:10.1038/cddis.2016.394

Nagila, A., Netsawang, J., Srisawat, C., Noisakran, S., Morchang, A., Yasamut, U., . . Limjindaporn, T. (2011). Role of CD137 signaling in dengue virus-mediated apoptosis.Biochemical and Biophysical Research Communications, 410 (3), 428-433. doi:10.1016/j.bbrc.2011.05.151

Nasirudeen, A. M. A., Li, W., \& Ding, X. L. (2008). Induction of p53-dependent and mitochondria-mediated cell death pathway by dengue virus infection of human and animal cells.Microbes 83 Infection, 10 (10), 1124-1132.

Netsawang, J., Noisakran, S., Puttikhunt, C., Kasinrerk, W., Wongwiwat, W., Malasit, P., . . Limjindaporn, T. (2010). Nuclear localization of dengue virus capsid protein is required for DAXX interaction and apoptosis. Virus Research, 147 (2), 275-283.

Netsawang, J., Panaampon, J., Khunchai, S., Kooptiwut, S., Nagila, A., Puttikhunt, C., . . Limjindaporn, T. (2014). Dengue virus disrupts Daxx and NF- $\chi$ B interaction to induce CD137-mediated apoptosis. Biochemical and Biophysical Research Communications, 450 (4), 1485-1491.

Nevalainen, T. J., \& Losacker, W. (1997). Serum phospholipase A2 in dengue. The Journal of infection, 35 (3), 251-252.

Ochoa, M. V., Cordero, J. G., Castañeda, B. G., Argumedo, L. S., Sepúlveda, N. V., \& Barrón, L. C. (2009). A clinical isolate of dengue virus and its proteins induce apoptosis in HMEC-1 cells: a possible implication in pathogenesis.Archives of Virology, 154 (6), 919-928.

Olagnier, D., Peri, S., Steel, C., van Montfoort, N., Chiang, C., Beljanski, V., . . Hiscott, J. (2014). Cellular oxidative stress response controls the antiviral and apoptotic programs in dengue virus-infected dendritic cells. PLoS Pathogens, 10 (12), e1004566. doi:10.1371/journal.ppat.1004566

Oyarzún-Arrau, A., Alonso-Palomares, L., Valiente-Echeverría, F., Osorio, F., \& Soto-Rifo, R. (2020). Crosstalk between RNA Metabolism and Cellular Stress Responses during Zika Virus Replication. Pathogens (Basel, Switzerland), 9 (3). doi:10.3390/pathogens9030158

Papaianni, E., El Maadidi, S., Schejtman, A., Neumann, S., Maurer, U., Marino-Merlo, F., . . . Borner, C. (2015). Phylogenetically Distant Viruses Use the Same BH3-Only Protein Puma to Trigger Bax/Bak-Dependent Apoptosis of Infected Mouse and Human Cells. PloS One, 10 (6), e0126645. doi:10.1371/journal.pone.0126645

Park, J. G., Avila-Perez, G., Madere, F., Hilimire, T. A., Nogales, A., Almazan, F., \& Martinez-Sobrido, L. (2019). Potent Inhibition of Zika Virus Replication by Aurintricarboxylic Acid. Frontiers in Microbiology, 10 , 718. doi:10.3389/fmicb.2019.00718

Parquet, M. D. C., Kumatori, A., Hasebe, F., Morita, K., \& Igarashi, A. (2001). West Nile virus-induced bax-dependent apoptosis. FEBS Letters, 500 (1), 17-24.

Peng, B.-H., \& Wang, T. (2019). West Nile Virus Induced Cell Death in the Central Nervous System.Pathogens (Basel, Switzerland), 8 (4). doi:10.3390/pathogens8040215 
Pobezinskaya, Y. L., \& Liu, Z. (2012). The role of TRADD in death receptor signaling. Cell cycle (Georgetown, Tex.), 11 (5), 871-876. doi:10.4161/cc.11.5.19300

Prikhod'Ko, G. G., Prikhod'Ko, E. A., Cohen, J. I., \& Pletnev, A. G. (2001). Infection with Langat Flavivirus or Expression of the Envelope Protein Induces Apoptotic Cell Death. Virology, 286 (2), 328-335.

Puthalakath, H., O’Reilly, L. A., Gunn, P., Lee, L., Kelly, P. N., Huntington, N. D., . . Strasser, A. (2007). ER stress triggers apoptosis by activating BH3-only protein Bim.Cell, 129 (7), 1337-1349.

Qian, X., Nguyen, H. N., Song, M. M., Hadiono, C., Ogden, S. C., Hammack, C., . . . Ming, G.-L. (2016). Brain-Region-Specific Organoids Using Mini-bioreactors for Modeling ZIKV Exposure. Cell, 165 (5), 12381254. doi:10.1016/j.cell.2016.04.032

Quaresma, J. A. S., Barros, V. L. R. S., Pagliari, C., Fernandes, E. R., Guedes, F., Takakura, C. F. H., . . Duarte, M. I. S. (2006). Revisiting the liver in human yellow fever: Virus-induced apoptosis in hepatocytes associated with TGF- $\beta$, TNF- $\alpha$ and NK cells activity. Virology, 345 (1), 22-30.

Ramanathan, M. P., Chambers, J. A., Pankhong, P., Chattergoon, M., Attatippaholkun, W., Dang, K., . . . Weiner, D. B. (2006). Host cell killing by the West Nile Virus NS2B-NS3 proteolytic complex: NS3 alone is sufficient to recruit caspase-8-based apoptotic pathway. Virology, 345 (1), 56-72.

Rastogi, M., Sharma, N., \& Singh, S. K. (2016). Flavivirus NS1: a multifaceted enigmatic viral protein. Virology Journal, 13 (1), 131.

Ribeiro, M. R., Moreli, J. B., Marques, R. E., Papa, M. P., Meuren, L. M., Rahal, P., . . . Nogueira, M. L. (2018). Zika-virus-infected human full-term placental explants display pro-inflammatory responses and undergo apoptosis. Archives of Virology, 163 (10), 2687-2699. doi:10.1007/s00705-018-3911-x

Rubio-Moscardo, F., Blesa, D., Mestre, C., Siebert, R., Balasas, T., Benito, A., . . Martinez-Climent, J. A. (2005). Characterization of 8p21.3 chromosomal deletions in B-cell lymphoma: TRAIL-R1 and TRAIL-R2 as candidate dosage-dependent tumor suppressor genes. Blood, 106 (9), 3214-3222.

S-O, C., T-J, C., Stone, G., ., C-H, C., \& J-J, L. (2006). Programmed cell death induced by Japanese encephalitis virus YL vaccine strain or its recombinant envelope protein in varied cultured cells. Intervirology, $49(6), 346-351$.

Samuel, M. A., Morrey, J. D., \& Diamond, M. S. (2007). Caspase 3-dependent cell death of neurons contributes to the pathogenesis of West Nile virus encephalitis. Journal of Virology, 81 (6), 2614-2623.

Sankar, B., Utsav, S., \& Sudhanshu, V. (2014). Regulated IRE1-dependent decay pathway is activated during Japanese encephalitis virus-induced unfolded protein response and benefits viral replication. Journal of General Virology, 95 (1), 71-79.

Schimmer, A. D. (2004). Inhibitor of apoptosis proteins: translating basic knowledge into clinical practice.Cancer Research, 64 (20), 7183-7190.

Shafee, N., \& AbuBakar, S. (2003). Dengue virus type 2 NS3 protease and NS2B-NS3 protease precursor induce apoptosis. The Journal of general virology, 84 (Pt 8), 2191-2195. doi:10.1099/vir.0.19022-0

Sherman, K. E., Rouster, S. D., Kong, L. X., Aliota, M. T., Blackard, J. T., \& Dean, G. E. (2019). Zika virus replication and cytopathic effects in liver cells. PloS One, 14 (3), e0214016. doi:10.1371/journal.pone.0214016

Silveira, G. F., Meyer, F., Delfraro, A., Mosimann, A. L. P., \& Santos, C. N. D. D. J. J. o. V. (2011). Dengue Virus Type 3 Isolated from a Fatal Case with Visceral Complications Induces Enhanced Proinflammatory Responses and Apoptosis of Human Dendritic Cells. 85 (11), 5374-5383.

Slomnicki, L. P., Chung, D. H., Parker, A., Hermann, T., Boyd, N. L., \& Hetman, M. (2017). Ribosomal stress and Tp53-mediated neuronal apoptosis in response to capsid protein of the Zika virus. Scientific 
Reports, 7 (1), 16652.

Smith, J. L., Grey, F. E., Uhrlaub, J. L., Janko, N. Z., \& Hirsch, A. J. (2012). Induction of the cellular microRNA, Hs_154, by West Nile virus contributes to virus-mediated apoptosis through repression of antiapoptotic factors. Journal of Virology, 86 (9), 5278.

Souza, B. S. F., Sampaio, G. L. A., Pereira, C. S., Campos, G. S., Sardi, S. I., Freitas, L. A. R., . . . Soares, M. B. P. (2016). Zika virus infection induces mitosis abnormalities and apoptotic cell death of human neural progenitor cells.Scientific Reports, 6 , 39775. doi:10.1038/srep39775

Sreekanth, G. P., Chuncharunee, A., Cheunsuchon, B., Noisakran, S., Yenchitsomanus, P. T., \& Limjindaporn, T. (2017). JNK1/2 inhibitor reduces dengue virus-induced liver injury.Antiviral Research, 141 , 7-18. doi:10.1016/j.antiviral.2017.02.003

Suliman, A., Lam, A., Datta, R., \& Srivastava, R. K. (2001). Intracellular mechanisms of TRAIL: apoptosis through mitochondrial-dependent and -independent pathways. Oncogene, 20 (17), 2122-2133.

Suwanmanee, S., \& Luplertlop, N. (2017). Immunopathogenesis of Dengue Virus-Induced Redundant Cell Death: Apoptosis and Pyroptosis. Viral Immunology, 30 (1), 13.

Suzuki, T., Okamoto, T., Katoh, H., Sugiyama, Y., Kusakabe, S., Tokunaga, M., . . . Matsuura, Y. (2018). Infection with flaviviruses requires BCLXL for cell survival. PLoS Pathogens, 14 (9), e1007299. doi:10.1371/journal.ppat.1007299

Tabas, I., \& Ron, D. (2011). Integrating the mechanisms of apoptosis induced by endoplasmic reticulum stress. Nature Cell Biology, 13 (3), 184-190. doi:10.1038/ncb0311-184

Tait, S. W. G., \& Green, D. R. (2010). Mitochondria and cell death: outer membrane permeabilization and beyond. Nature reviews. Molecular cell biology, 11 (9), 621-632. doi:10.1038/nrm2952

Tan, Z., Zhang, W., Sun, J., Fu, Z., Ke, X., Zheng, C., . . . Zheng, Z. (2018). ZIKV infection activates the IRE1-XBP1 and ATF6 pathways of unfolded protein response in neural cells. Journal of Neuroinflammation, 15 (1), 275. doi:10.1186/s12974-018-1311-5

Tang, H., Hammack, C., Ogden, S. C., Wen, Z., Qian, X., Li, Y., . . . Ming, G.-L. (2016). Zika Virus Infects Human Cortical Neural Progenitors and Attenuates Their Growth.Cell stem cell, 18 (5), 587-590. doi:10.1016/j.stem.2016.02.016

Tao, Y., Dabing, Z., Xuejun, M., Zhenzhen, C., Liu, C., Zheng, N., . . . Yan, Z. J. J. o. V. (2012). Complete genome sequence of a novel flavivirus, duck tembusu virus, isolated from ducks and geese in china. Journal of Virology, 86 (6), 3406-3407.

Teng, Y., Liu, S., Guo, X., Liu, S., Jin, Y., He, T., . . . Tong, Y. (2017). An Integrative Analysis Reveals a Central Role of P53 Activation via MDM2 in Zika Virus Infection Induced Cell Death. Front Cell Infect Microbiol, 7 , 327. doi:10.3389/fcimb.2017.00327

Thepparit, C., Khakpoor, A., Khongwichit, S., Wikan, N., Fongsaran, C., Chingsuwanrote, P., . . . Smith, D. R. (2013). Dengue 2 infection of HepG2 liver cells results in endoplasmic reticulum stress and induction of multiple pathways of cell death. BMC Research Notes, 6 , 372. doi:10.1186/1756-0500-6-372

Torrentes-Carvalho, A., Azeredo, E. L., Reis, S. R., Miranda, A. S., Gandini, M., Barbosa, L. S., \& Kubelka, C. F. (2009). Dengue-2 infection and the induction of apoptosis in human primary monocytes. Memorias do Instituto Oswaldo Cruz, 104 (8), 1091-1099.

Tsao, C. H., Su, H. L., Lin, Y. L., Yu, H. P., Kuo, S. M., Shen, C. I., . . . Liao, C. L. (2008). Japanese encephalitis virus infection activates caspase-8 and -9 in a FADD-independent and mitochondrion-dependent manner. Journal of General Virology, 89 (Pt 8), 1930-1941. doi:10.1099/vir.0.2008/000182-0 
Upton, J.-P., Wang, L., Han, D., Wang, E. S., Huskey, N. E., Lim, L., . . . Oakes, S. A. (2012). IRE1 $\alpha$ cleaves select microRNAs during ER stress to derepress translation of proapoptotic Caspase-2. Science (New York, N.Y.), 338 (6108), 818-822. doi:10.1126/science.1226191

Urbanowski, M. D., \& Hobman, T. C. (2013). The West Nile virus capsid protein blocks apoptosis through a phosphatidylinositol 3-kinase-dependent mechanism. Journal of Virology, 87 (2), 872-881.

Vaidyanathan, R., \& Scott, T. W. (2006). Apoptosis in mosquito midgut epithelia associated with West Nile virus infection. Apoptosis, 11 (9), 1643.

van Loo, G., van Gurp, M., Depuydt, B., Srinivasula, S. M., Rodriguez, I., Alnemri, E. S., . . . Vandenabeele, P. (2002). The serine protease Omi/HtrA2 is released from mitochondria during apoptosis. Omi interacts with caspase-inhibitor XIAP and induces enhanced caspase activity. Cell Death and Differentiation, 9 (1), 20-26.

Verma, G., \& Datta, M. (2012). The critical role of JNK in the ER-mitochondrial crosstalk during apoptotic cell death. Journal of Cellular Physiology, 227 (5), 1791-1795. doi:10.1002/jcp.22903

Wajant, H. (2002). The Fas signaling pathway: more than a paradigm. Science (New York, N.Y.), 296 (5573), 1635-1636.

Wanjun, Z., Jidang, C., Chunya, W., Heng, W., Zhen, H., Minze, Z., . . . Guihong, Z. J. J. o. V. (2012). Complete genome sequence of duck Tembusu virus, isolated from Muscovy ducks in southern China. Journal of Virology, 86 (23), 13119.

Weng, J.-R., Hua, C.-H., Chen, C.-H., Huang, S.-H., Wang, C.-Y., Lin, Y.-J., . . . Lin, C.-W. (2018). Anti-apoptotic activity of Japanese encephalitis virus NS5 protein in human medulloblastoma cells treated with interferon- $\beta$. Journal of microbiology, immunology, and infection $=$ Wei mian yu gan ran za zhi, 51 (4), 456-464. doi:10.1016/j.jmii.2017.01.005

Wong, W. W.-L., \& Puthalakath, H. (2008). Bcl-2 family proteins: the sentinels of the mitochondrial apoptosis pathway. IUBMB life, 60 (6), 390-397. doi:10.1002/iub.51

Xiao, C., \& Ghosh, S. (2005). NF-kappaB, an evolutionarily conserved mediator of immune and inflammatory responses. Advances in Experimental Medicine and Biology, 560 , 41-45.

Yan, Y., Zhang, X. T., Wang, G., Cheng, X., Yan, Y., Fu, Y. J., . . . Jiang, Z. (2019). Zika virus induces abnormal cranial osteogenesis by negatively affecting cranial neural crest development. Infection, Genetics and Evolution, 69 , 176-189. doi:10.1016/j.meegid.2019.01.023

Yang, M., Lee, S., Oh, W., Lee, E., Yeh, J., Nah, J., . . . Pyo, S. (2010). West Nile virus capsid protein induces p53-mediated apoptosis via the sequestration of HDM2 to the nucleolus. Cellular Microbiology, 10 (1), 165-176.

Yang, T. C., Shiu, S. L., Chuang, P. H., Lin, Y. J., Wan, L., Lan, Y. C., \& Lin, C. W. (2009). Japanese encephalitis virus NS2B-NS3 protease induces caspase 3 activation and mitochondria-mediated apoptosis in human medulloblastoma cells. Virus Research, 143 (1), 77-85. doi:10.1016/j.virusres.2009.03.007

Ye, J., Rawson, R. B., Komuro, R., Chen, X., Davé, U. P., Prywes, R., . . Goldstein, J. L. (2000). ER stress induces cleavage of membrane-bound ATF6 by the same proteases that process SREBPs. Molecular Cell, 6 (6), 1355-1364.

Yiang, G. T., Chen, Y. H., Chou, P. L., Chang, W. J., Wei, C. W., \& Yu, Y. L. (2013). The NS3 protease and helicase domains of Japanese encephalitis virus trigger cell death via caspasedependent and independent pathways. Mol Med Rep, 7 (3), 826-830. doi:10.3892/mmr.2013.1261

Yu, C.-Y., Hsu, Y.-W., Liao, C.-L., \& Lin, Y.-L. (2006). Flavivirus infection activates the XBP1 pathway of the unfolded protein response to cope with endoplasmic reticulum stress. Journal of Virology, 80 (23), 11868-11880. 
Yu, I. M., Zhang, W., Holdaway, H. A., Li, L., Kostyuchenko, V. A., Chipman, P. R., . . Chen, J. (2008). Structure of the immature dengue virus at low $\mathrm{pH}$ primes proteolytic maturation. Science (New York, N.Y.), 319 (5871), 1834-1837. doi:10.1126/science.1153264

Yuan, S., \& Akey, C. W. (2013). Apoptosome structure, assembly, and procaspase activation. Structure (London, England : 1993), 21 (4), 501-515. doi:10.1016/j.str.2013.02.024

Zhang, F., Hammack, C., Ogden, S. C., Cheng, Y., Lee, E. M., Wen, Z., . . . Jin, P. (2016). Molecular signatures associated with ZIKV exposure in human cortical neural progenitors. Nucleic Acids Research, 44 (18), 8610-8620.

Table 1. Pro-apoptotic or anti-apoptotic activity of DENV and its proteins.

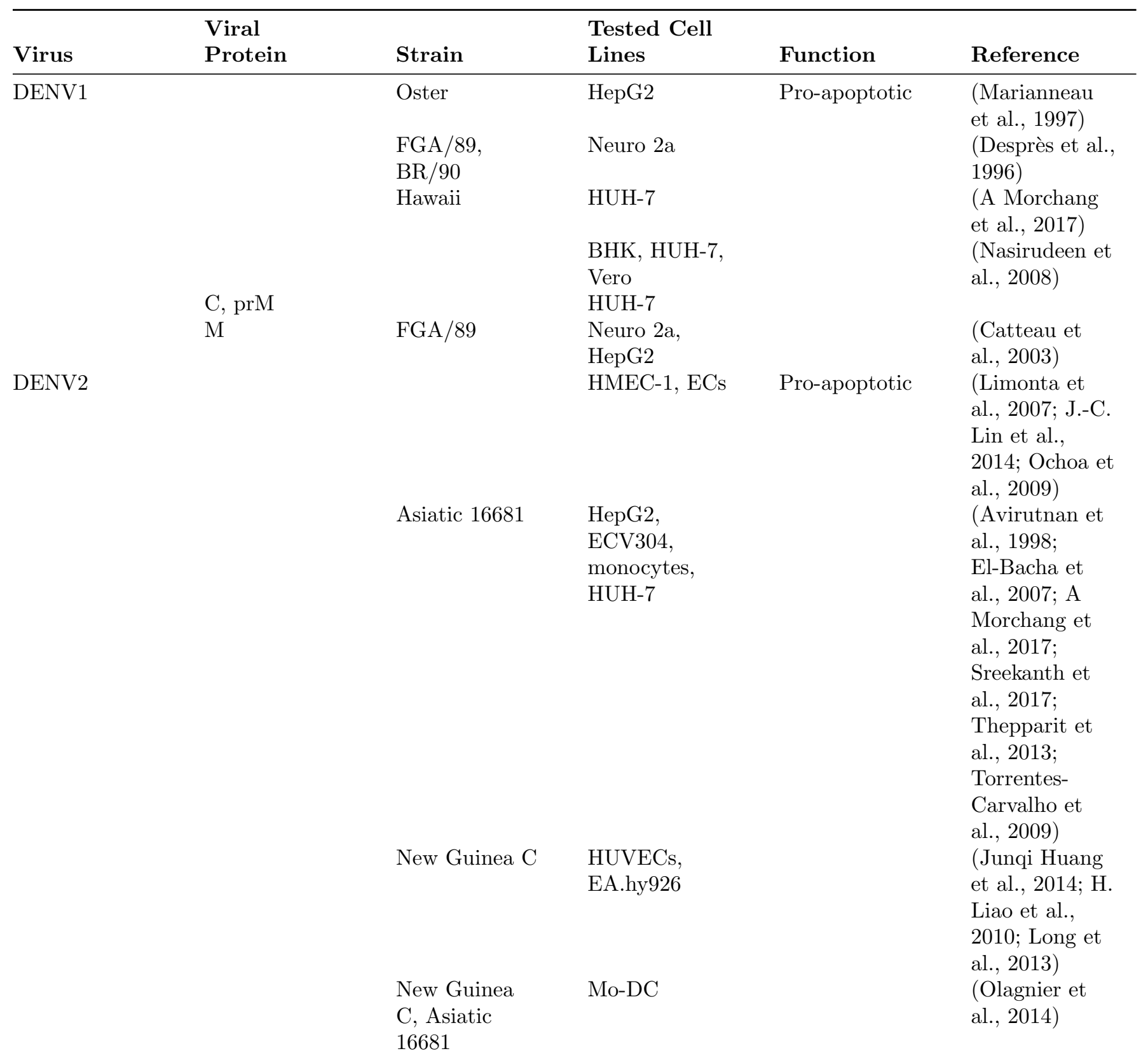




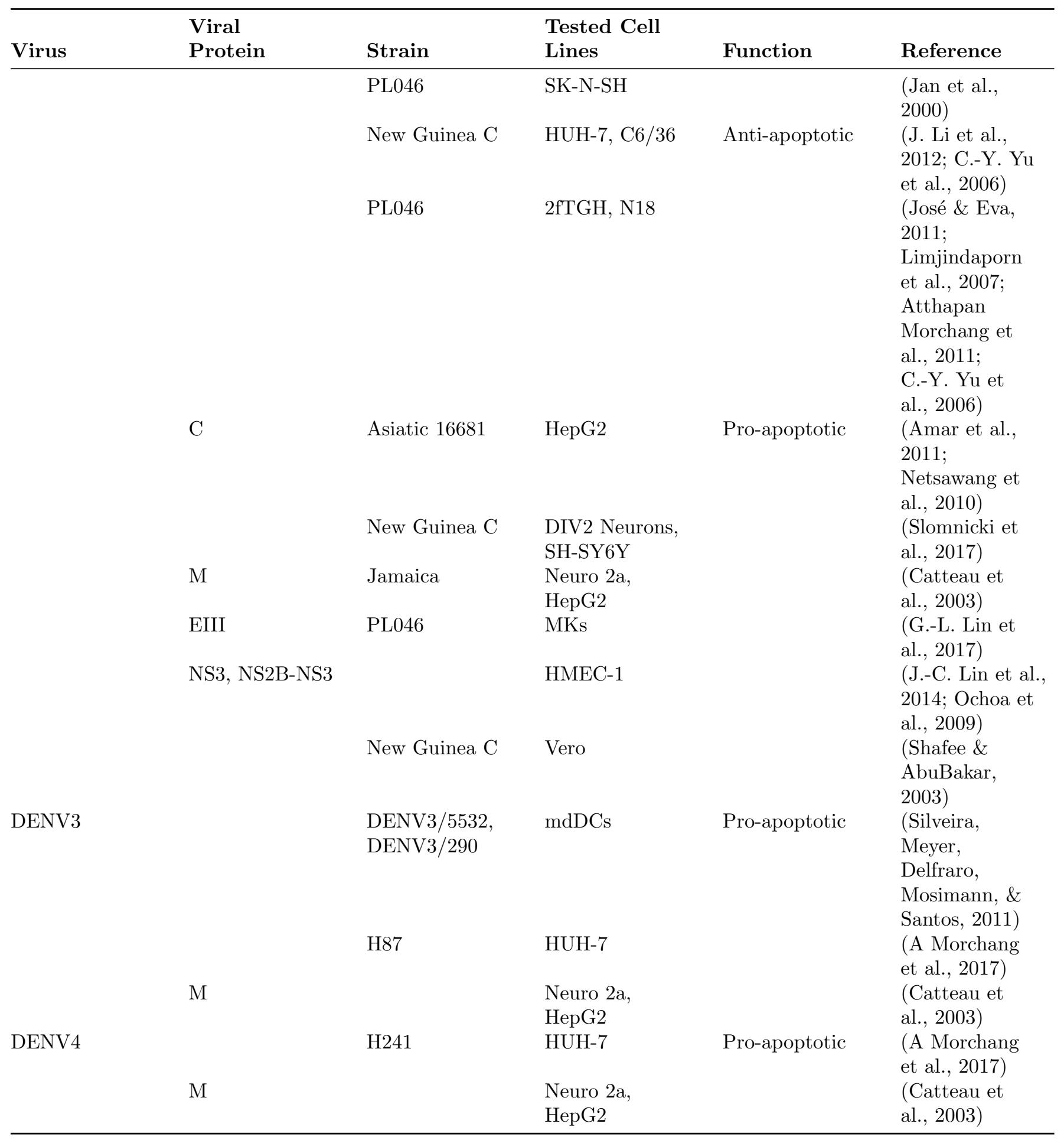

Table 2. Pro-apoptotic or anti-apoptotic activity of WNV and its proteins. 


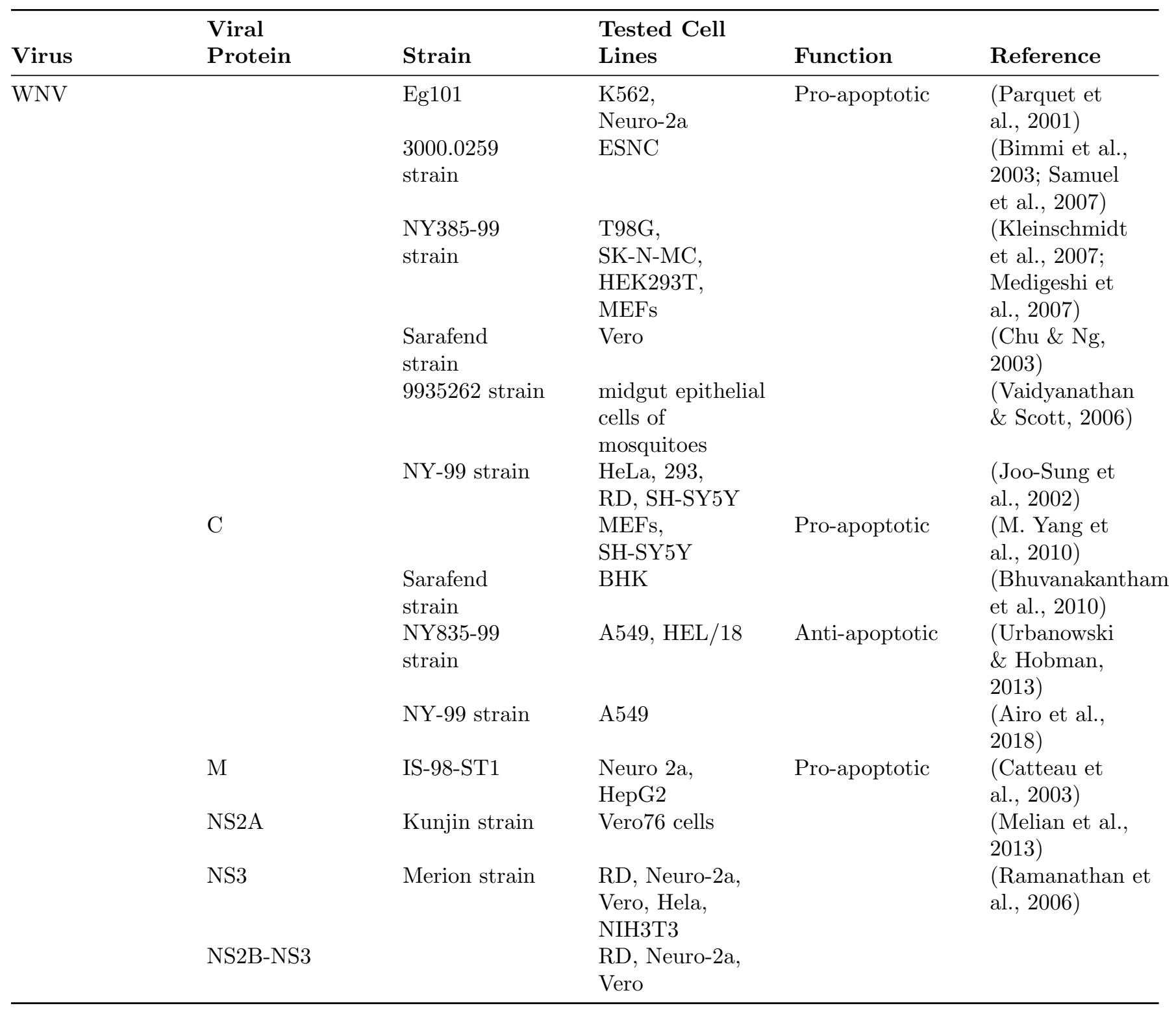

Table 3. Pro-apoptotic or anti-apoptotic activity of JEV and its proteins.

\begin{tabular}{|c|c|c|c|c|c|}
\hline Virus & Viral Protein & Strain & Tested Cell Lines & Function & Reference \\
\hline \multirow[t]{10}{*}{$\overline{J E V}$} & & & hNS1 & Pro-apoptotic & (Mukherjee et al., 2017) \\
\hline & & RP-9 & BHK-21, N18, NT2, MCF7, CHO cells & & (Hong-Lin et al., 2002; ] \\
\hline & & SA14-14-2 & BHK-21 & & (M. Huang et al., 2016) \\
\hline & & P3 & Neuro-2a & & (R.-J. Lin et al., 2004) \\
\hline & & $\mathrm{T} 1 \mathrm{P} 1$ & TE671 & & (T. C. Yang et al., 2009) \\
\hline & & JEV-YL & HepG2, Vero & & (S-O et al., 2006) \\
\hline & & RP-9 & N18 & Anti-apoptotic & (C.-Y. Yu et al., 2006) \\
\hline & $\mathrm{C}$ & & A549 & Anti-apoptotic & (Airo et al., 2018) \\
\hline & M & Nakayama & Neuro 2a, HepG2 & Pro-apoptotic & (Catteau et al., 2003) \\
\hline & $\mathrm{E}$ & JEV-YL & HepG2, Vero & & (S-O et al., 2006) \\
\hline
\end{tabular}




\begin{tabular}{|c|c|c|c|c|c|}
\hline Virus & Viral Protein & Strain & Tested Cell Lines & Function & Reference \\
\hline & NS3 & \multirow{3}{*}{$\mathrm{T} 1 \mathrm{P} 1$} & Vero,HeLa & & (Yiang et al., 2013) \\
\hline & NS2B-NS3 & & TE671 & & (T. C. Yang et al., 2009) \\
\hline & NS5 & & & Anti-apoptotic & (Weng et al., 2018) \\
\hline
\end{tabular}

Table 4. Pro-apoptotic or anti-apoptotic activity of ZIKV and its proteins.

\begin{tabular}{|c|c|c|c|c|c|}
\hline Virus & Viral Protein & Strain & Tested Cell Lines & Function & Reference \\
\hline ZIKV & & $\begin{array}{l}\text { KU940228 } \\
\text { MR766 } \\
\text { ZG-01 } \\
\text { ZIKV-LAV } \\
\text { Paraiba strain } \\
\text { PF13 } \\
\text { SZ01 } \\
\text { ZIKA-BR } \\
\text { PRVABC59 } \\
\text { PRVABC59, MR766 } \\
\text { PRVABC59, Dakar } \\
\text { PRVABC59, FLR strain } \\
\text { MR766, FSS13025 }\end{array}$ & $\begin{array}{l}\text { neural parenchyma } \\
\text { NPCs } \\
\text { NPCs, RPTEpiCs, IPCs } \\
\text { renal cells } \\
\text { GSCs } \\
\text { Vero, A549 } \\
\text { hNPCs } \\
\text { CCF-STTG1, SK-N-SH } \\
\text { placental tissues } \\
\text { Huh7.5 and HepG2 cells } \\
\text { hNSCs } \\
\text { A549 } \\
\text { HEK293 } \\
\text { hNPCs }\end{array}$ & Pro-apoptotic & $\begin{array}{l}\text { (de Sousa et al., 201 } \\
\text { (Souza et al., 2016) } \\
\text { (J. Chen et al., 2017 } \\
\text { (T. Liu et al., 2019) } \\
\text { (Q. Chen et al., 201 } \\
\text { (Park et al., 2019) } \\
\text { (Ghouzzi et al., 201 } \\
\text { (Tan et al., 2018) } \\
\text { (Ribeiro et al., 2018 } \\
\text { (Sherman et al., 201 } \\
\text { (Devhare et al., 201 } \\
\text { (McFadden et al., 2 } \\
\text { (H. Liu et al., 2019) } \\
\text { (Zhang et al., 2016) }\end{array}$ \\
\hline & $\mathrm{C}$ & & U87 cells & Pro-apoptotic & $\begin{array}{l}\text { (Teng et al., 2017) } \\
\text { (Slomnicki et al. } 20\end{array}$ \\
\hline & PrM & $\begin{array}{l}\text { strain BeH819966 } \\
\text { MR776 }\end{array}$ & & & $\begin{array}{l}\text { (Slomnicki et al., } 20 \\
\text { (G. Li et al., 2019) }\end{array}$ \\
\hline & $\mathrm{E}$ & Haiti strain & $\begin{array}{l}\text { fNSCs } \\
\text { PC12 cells }\end{array}$ & & $\begin{array}{l}\text { (Bhagat et al., 2018 } \\
\text { (J. Liu et al., 2018) }\end{array}$ \\
\hline Virus & Viral Protein & Strain & Tested Cell Lines & Function & Reference \\
\hline YFV & $\mathrm{C}$ & BeH622205, BeH413820 & $\begin{array}{l}\text { HepG2 cell } \\
\text { A549 cells }\end{array}$ & $\begin{array}{l}\text { Pro-apoptotic } \\
\text { Anti-apoptotic }\end{array}$ & $\begin{array}{l}\text { (Holanda et al., 2019) } \\
\text { (Airo et al., 2018) }\end{array}$ \\
\hline LGTV & $\begin{array}{l}\mathrm{M} \\
\mathrm{E}\end{array}$ & $\begin{array}{l}\text { 17D-204 } \\
\text { clone } 636\end{array}$ & $\begin{array}{l}\text { Neuro 2a, HepG2 } \\
\text { Vero, LLC-MK2, Neuro-2a } \\
\text { Vero, Neuro-2a }\end{array}$ & $\begin{array}{l}\text { Pro-apoptotic } \\
\text { Pro-apoptotic }\end{array}$ & $\begin{array}{l}\text { (Catteau et al., 2003) } \\
\text { (Prikhod'Ko et al., } 20\end{array}$ \\
\hline $\begin{array}{l}\text { TBEV } \\
\text { LIV }\end{array}$ & & $\begin{array}{l}\text { Neudorfl H2J } \\
\text { LI3/1 }\end{array}$ & IRE/CTVM20 & $\begin{array}{l}\text { Pro-apoptotic } \\
\text { Pro-apoptotic }\end{array}$ & (Mansfield et al., 2017 \\
\hline $\begin{array}{l}\text { MVEV } \\
\text { SLV }\end{array}$ & $\mathrm{C}$ & & A549 cells & Anti-apoptotic & (Airo et al., 2018) \\
\hline
\end{tabular}

Table 5. Pro-apoptotic or anti-apoptotic activity of other flavivirus and its proteins.

Figure legend

Figure 1. The structure of the flavivirus genome. The protein is cleaved co- and post-translationally to form capsid (C), membrane (M) and envelope (E) structural proteins and nonstructural proteins (NS)-1, $2 \mathrm{~A}, 2 \mathrm{~B}, 3,4 \mathrm{~A}, 4 \mathrm{~B}$ and 5 .

Figure 2. The Flavivirus life cycle. 1) The viruses attach to the surface of a host cell and internalize by 
receptor-mediated endocytosis. 2) Acidification of the endosomal vesicle triggers conformational changes in the virion, fusion of the viral envelope and cell membranes, releasing the viral genome into the cytoplasm. 3) The positive-sense RNA is translated into a single polyprotein that is processed co- and post-translationally by viral and host proteases. The viral RNA-dependent RNA polymerase replicates the viral genome in specialized ER-derived membrane compartments. 4) Virus assembly occurs on the surface of the ER, the immature viral particles bearing prM and E bud into ER rumen after nucleocapsid formation with viral RNA. The resultant non-infectious, immature viral are transported to the trans-Golgi network (TGN). 5) The host protease furin cleaved of $\mathrm{prM}$ to $\mathrm{M}$, generating mature infectious particles. 6) Mature virions are subsequently released by exocytosis.

Figure 3. The intrinsic apoptotic pathway. The intrinsic cell death pathway is activated by an intracellular death signal. (a) This signal results in the oligomerization and translocation of Bak and Bax into the outer membrane of the mitochondria. This triggers mitochondrial outer membrane permeabilization (MOMP) and the release of Cyt-c and IAP binding proteins. Cyt-c forms a complex with pro-caspase-9 and Apaf-1, leading to activation of caspase-9, then caspase-9 activates the executioner caspases (caspase-3, -6, and -7) and induces cell death. The IAP binding proteins, such as Diablo and HtrA2, enhance caspase activation through the neutralization of IAPs. (b) Under ER stress, three upstream signaling proteins, IRE1, PERK and ATF6, are activated, thus leading to a cascade of activity that induces apoptosis. (b1) The prolonged activation of IRE1 can promote apoptosis. Phosphorylated IRE1 recruits TRAF2 and triggers a cascade of phosphorylation events, such as the activation of ASK1, which ultimately phosphorylates and activates JNK. Then, JNK phosphorylation activates pro-apoptotic genes and induces apoptosis through the mitochondrial pathway. (b2) The homomultimerization and autophosphorylation of PERK leads to eIF-2 $\alpha$ phosphorylation, which increases the translation of ATF4. Then, ATF4 upregulates the expression of CHOP, which promotes apoptosis. (b3) ATF6 migrates to the Golgi apparatus to undergo cleavage, first by S1P and then by S2P, cleaved ATF6 can also promote apoptosis via upregulation of CHOP.

Figure 4. The extrinsic apoptotic pathway. The extrinsic pathway is activated by death signals mediated by death ligands. (a) Fas and DR4/5 are activated by the binding of their respective ligands FasL and TRAIL; the receptors then bind to FADD via the DD. Then, the DED of FADD binds to procaspase-8/10, which forms a complex called the DISC and sends a signal to activate caspase- 8 and -10 , then caspase- 8 and -10 induce the activation of the caspase cascade and ultimately results in apoptosis. (b) In particular cells, the extrinsic pathway crosstalks with the intrinsic pathway through caspase-8-mediated truncation of Bid to tBid. tBid activates BAK/BAX oligomerization and induces apoptosis through the mitochondrial pathway. (c) TNFR1 is activated by the binding of its respective ligand TNF $\alpha$. TNFR1 recruits TRADD, an adaptor protein that binds to TRAFs, RIP1 and IAPs, forming the initial membrane complex (complex I), which stimulates the NF- $x$ B pathways to facilitate apoptosis. (d) Complex I forms two types of cytoplasmic apoptotic complexes, TRADD-dependent complex IIA and RIP1-dependent complex IIB, which activate caspase-8, thus initiating apoptosis.

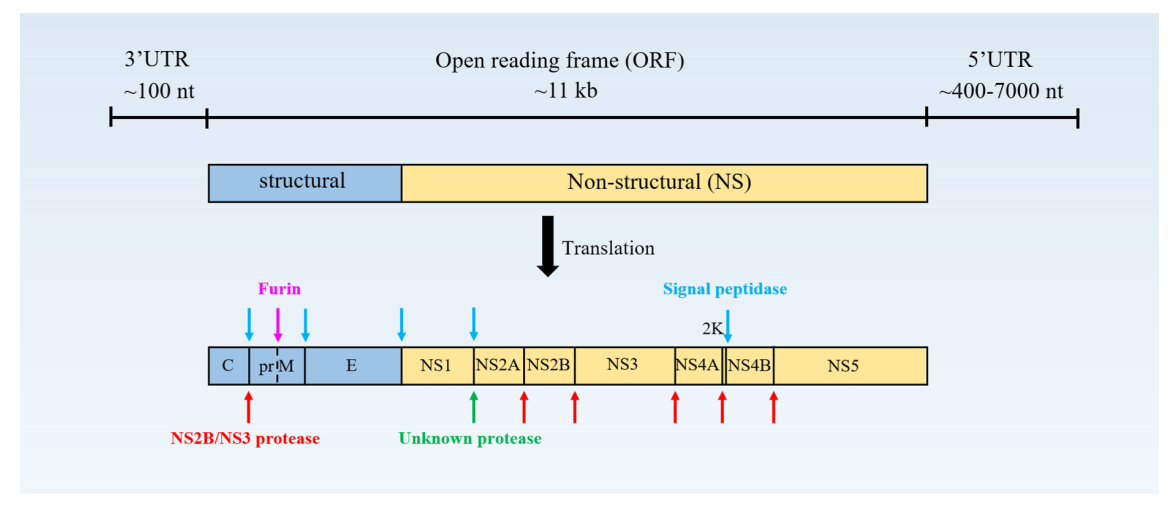



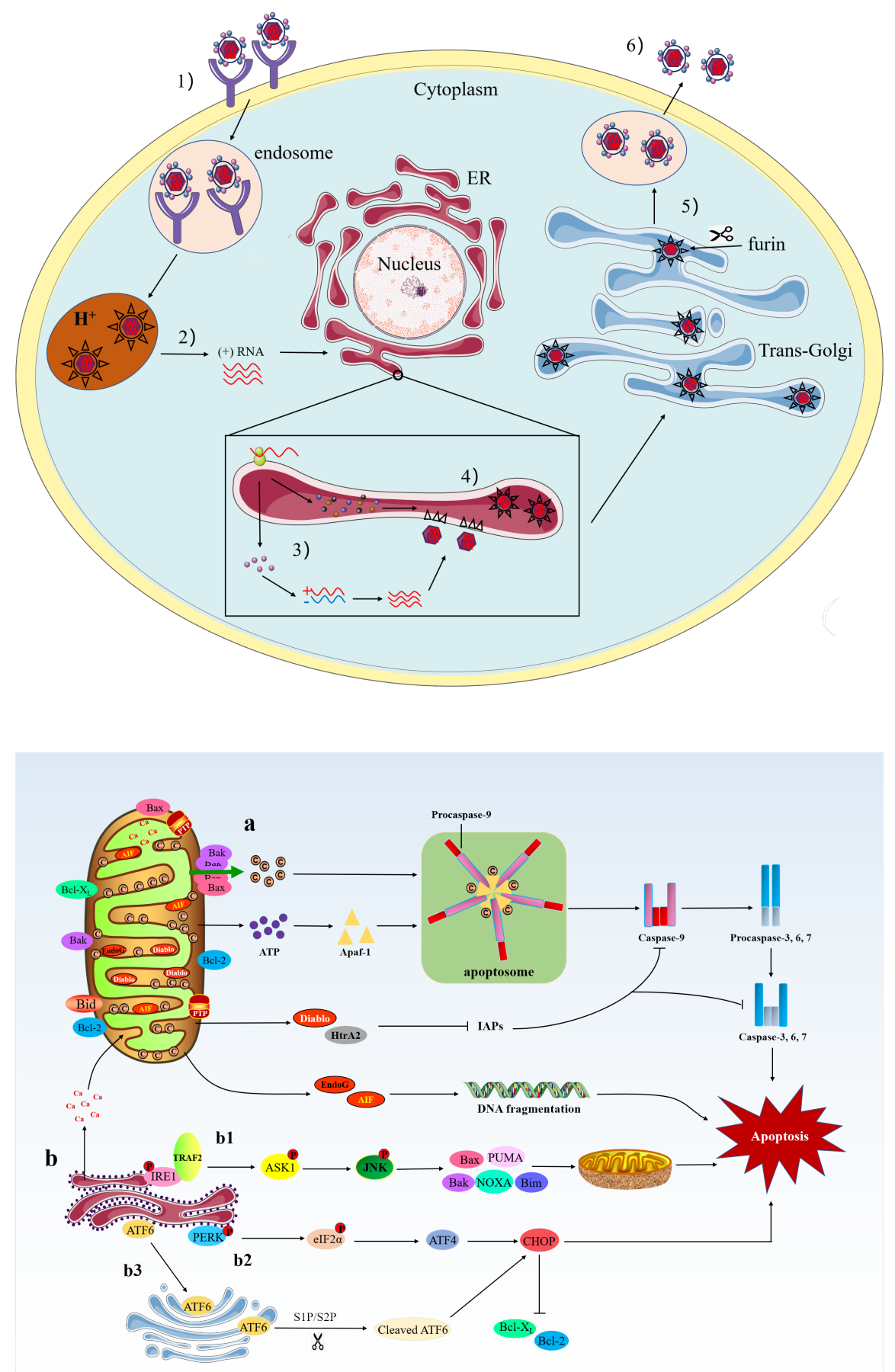


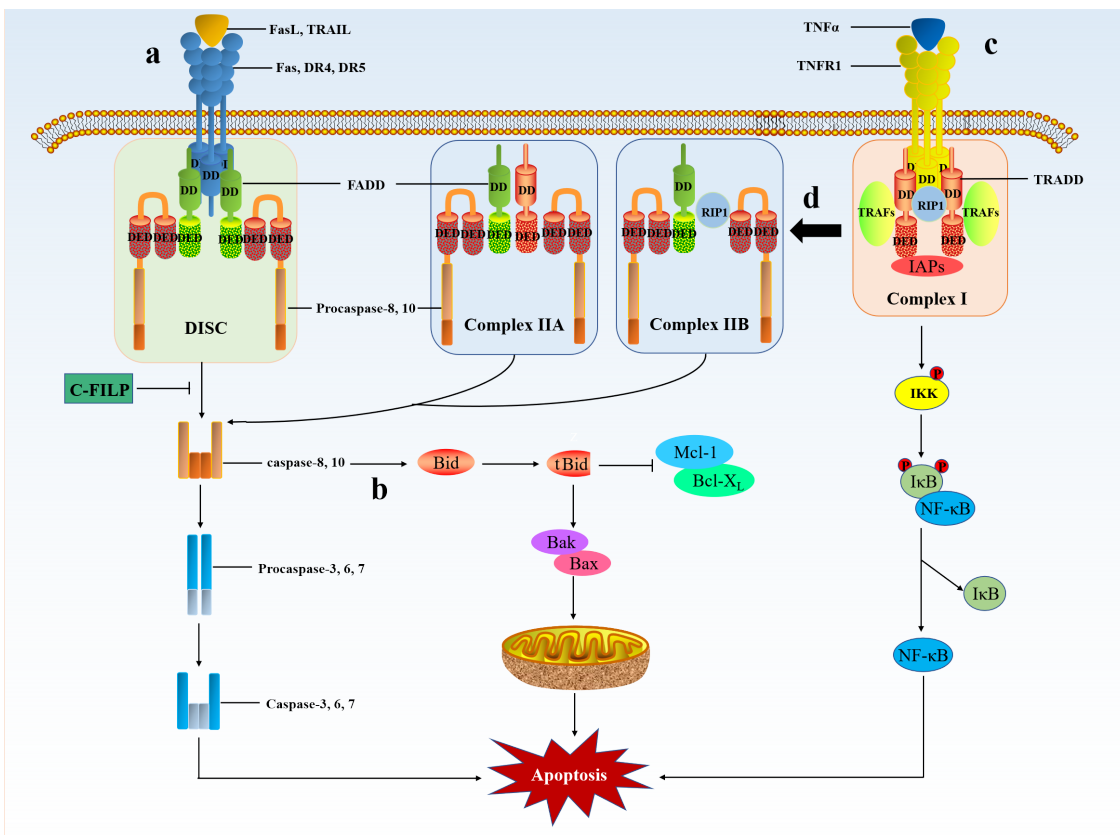

\section{Hosted file}

Table 1.xlsx available at https://authorea.com/users/380306/articles/496356-the-dualregulation-of-apoptosis-by-flavivirus

\section{Hosted file}

Table 2.xlsx available at https://authorea.com/users/380306/articles/496356-the-dualregulation-of-apoptosis-by-flavivirus

\section{Hosted file}

Table 3.xlsx available at https://authorea.com/users/380306/articles/496356-the-dualregulation-of-apoptosis-by-flavivirus

\section{Hosted file}

Table 4.xlsx available at https://authorea.com/users/380306/articles/496356-the-dualregulation-of-apoptosis-by-flavivirus

\section{Hosted file}

Table 5.xlsx available at https://authorea.com/users/380306/articles/496356-the-dualregulation-of-apoptosis-by-flavivirus 